\title{
Effects of soil-structure interaction on the dynamic properties and seismic response of piled structures *
}

\author{
Cristina Medina, Juan J. Aznárez, Luis A. Padrón, Orlando Maeso \\ Instituto Universitario de Sistemas Inteligentes y Aplicaciones Numéricas en Ingeniería \\ (SIANI) Universidad de Las Palmas de Gran Canaria \\ Edificio Central del Parque Científico y Tecnológico \\ Campus Universitario de Tafira, 35017, Las Palmas de Gran Canaria, Spain \\ \{cmedina, jjaznarez, lpadron, omaeso\}@siani.es, web: http://www.siani.es
}

3 August 2013

\begin{abstract}
This paper presents a simple and stable procedure for the estimation of periods and dampings of piled shear buildings taking soil-structure interaction into account. A substructuring methodology that includes the three-dimensional character of the foundations is used. The structure is analyzed as founded on an elastic homogeneous half-space and excited by vertically-incident $\mathrm{S}$ waves. The strategies proposed in the literature to estimate the period and damping are revised, and a modified strategy is proposed including crossed impedances and all damping terms. Ready-to-use graphs are presented for the estimation of flexiblebase period and damping in terms of their fixed-base values and the system configuration. Maximum shear forces together with base displacement and rocking peak response are also provided. It is shown that cross-coupled impedances and kinematic interaction factors need to be taken into account to obtain accurate results for piled buildings.
\end{abstract}

\section{INTRODUCTION}

When analysing the seismic behaviour of structures, kinematic and inertial effects associated to soil-structure interaction (SSI) affect the dynamic characteristics of the interacting system and influence the ground motion around the foundation. Thus, it is important to assess the variations of the system period associated with the soil stiffness, as well as the variations of the modal damping associated with the material damping in the soil and especially with the radiation effects.

The effects of SSI on the dynamic characteristics of soil-structure systems have been widely studied both for shallow foundations $[1,2,3,4,5,6]$ and for embedded foundations using both 3D models [7, 8, 9, 10] and 2D models [11, 12]. The papers by Jenning and Bielak [4], Veletsos and Meek [2], Luco [5], Wolf [6] or Bielak [7], all introduce the analogy of a fixed-base replacement SDOF oscillator whose period and damping can represent the dynamic behaviour of the structure-foundation system. In all these pioneering works, some simplifying assumptions were used in order to obtain results or expressions for the effective system period and damping: the influence of the coupled terms of the soil-impedance matrix was neglected and, for embedded foundations, the kinematic effects of the incident wave were not considered, using as base excitation a horizontal harmonic motion with constant amplitude. In contrast, the effects of the foundation embedment considering both kinematic and inertial interaction were taken into account by Avilés and Pérez-Rocha [9] (for 3D rectangular foundations), by Avilés and Suárez [13]

\footnotetext{
${ }^{*}$ Draft of the paper originally published in Soil Dynamics and Earthquake Engineering 2013; 53:160-175. http://dx.doi.org/10.1016/j.soildyn.2013.07.004. This work is released with a Creative Commons Attribution Non-Commercial No derivatives License.
} 
(for axisymmetrical embedded foundations in a layer), and by Todorovska [11] and Todorovska and Trifunac $[14,12]$ who presented a 2D model with analytical solutions for impedances and kinematic effects for very long buildings founded on rigid cylindrical foundations. Also, Todorovska and Trifunac [14, 12] and Avilés et al. [10] for problems with square embedded foundations, studied the effects of the type of waves and their angle of incidence on the system frequency and damping.

Regarding pile-supported buildings, and to the extent of the authors' knowledge, there are few studies in the scientific literature examining the effects of SSI on their dynamic characteristics $[15,16,17,18]$. Rainer [15] used a substructuring methodology to analyse the modal damping of a superstructure supported on piles. Kaynia and Mahzooni [16] used a three-dimensional Green's functions-based formulation, for the pile foundation, and a single-degree-of-freedom (SDOF) model for the structure, in order to calculate the seismic shear forces in the piles during the seismic kinematic and inertial interaction phases for different pile foundations. On the other hand, Aguilar and Avilés [17] analysed piled foundations by extending the Avilés and PérezRocha's [9] procedure for embedded foundations and thus they studied the SSI effects on the system period and damping for a specific configuration of $8 \times 8$ piles. Moreover, Maravas et al. [18] presented a simple methodology in order to study SSI effects on single-pile supported one-storey shear structures by obtaining its period and damping. However, there are no parametric studies of this nature for piled foundations consisting of a variable number of piles, with different embedment and spacing between them.

Following the reference works for shallow and embedded foundations systems, the aim of this work is to evaluate the influence of SSI on the period and damping of shear structures founded on square pile groups embedded in homogeneous viscoelastic half-spaces subjected to vertically-incident $\mathrm{S}$ waves. The analysis is performed by a substructuring model in the frequency domain that takes into account both kinematic and inertial interaction effects. In this study, the harmonic response of the soil-structure system is obtained by making use of impedance functions and kinematic interaction factors computed by a BEM-FEM coupling model developed by Padrón et al. [19].

The effective period and damping of the interacting system $(\tilde{T}$ and $\tilde{\xi})[8,9,2,7,14]$ represent the dynamic parameters of an equivalent viscously damped SDOF system excited by the freefield ground motion. This replacement oscillator will reproduce, as accurately as possible, the coupled system response within the range where the peak response occurs. A comparative review of the different strategies used in the literature for establishing this equivalence and calculating the parameters of this single-degree-of-freedom system is presented, identifying those that best suit to the problem under study and proposing a modification. Thus, a simplified and stable procedure, which takes into account all the elements of the matrix of impedances, is developed herein. The accuracy of this simplified procedure is assessed through comparisons with the solution obtained from the iterative resolution of a complex-valued system of equations which represents the equation of motion of the interacting system. Results in terms of period $\tilde{T} / T$ and damping $\tilde{\xi}$ for different pile configurations are provided in ready-to-use graphs that can be used to build modified response spectra that include SSI effects.

All equations are expressed in terms of the main dimensionless parameters of the problem which considerably facilitates the analysis of their influence on the system dynamic response. The influence of the more important parameters involved (wave parameter, slenderness ratio, spacing between adjacent piles, embedment ratio and number of piles) is analysed over practical ranges of interest. Moreover, the influence of the consideration of the cross-coupled impedance and the kinematic interaction factors for the pile-groups configurations is also studied.

\section{PROBLEM DEFINITION}

The dynamic response of pile-supported linear shear structures is investigated in this work making use of a single-degree-of-freedom system in its fixed-base condition, as the one depicted 
in Figure 1, that may represent either one-storey structures or one mode of vibration of multistorey buildings. The superstructure can be defined by its fixed-base period $T$, its mass $m$, the structural stiffness $k$, the height $h$ of the resultant of the inertia forces for the mode, the moment of inertia of the vibrating mass $I$, and the viscous damping ratio $\xi$. The structure is considered to be founded on a square pile group embedded in a homogeneous, viscoelastic and isotropic half-space, as depicted in Figure 1. It is assumed that the pile heads are constrained by a rigid pile cap, considered as a rigid square plate of negligible thickness, which is not in contact with the half-space. The pile group is defined by length $L$ and sectional diameter $d$ of piles, centre-to-centre spacing between adjacent piles $s$, cap mass $m_{o}$, and cap moment of inertia about the centre of gravity of the cap $I_{o}$. The foundation halfwidth is denoted by $b$. The columns of the structure are assumed to be massless and axially inextensible. Both the foundation mass and the mass of the structure are presumed to be uniformly distributed over square areas. This model of the foundation-structure system is an enhancement of that which appears to have been first used by Parmelee [20] in 1967 for shallow foundations and, according to Veletsos and Meek [2], has formed the basis of most subsequent investigations.
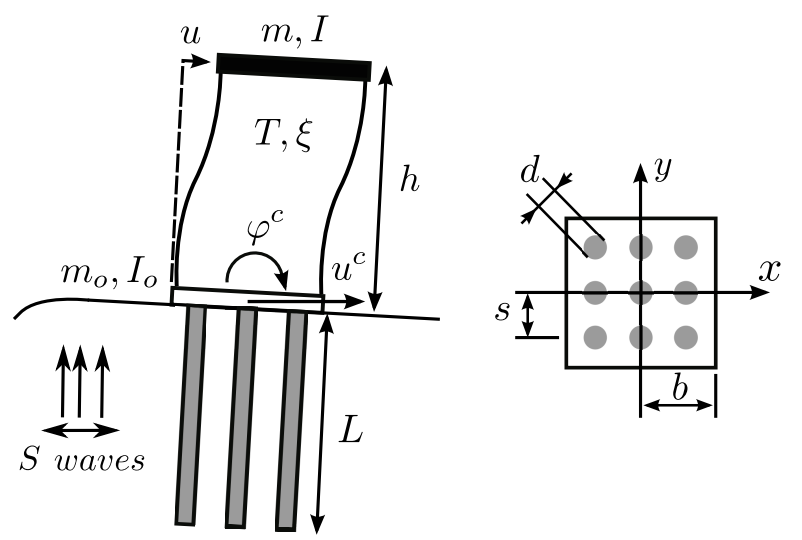

Figure 1: Problem definition. Single shear structure supported on a piled foundation embedded in a homogeneous half-space under vertically-incident $S$ waves

If SSI is taken into account, the system behaviour can be approximated by that of a threedegree-of-freedom system, defined by the foundation horizontal displacement $u^{c}$ and rocking $\varphi^{c}$, together with the structural horizontal deflection $u$. (Note that rocking of pile cap and structure are identical). The system is subjected to vertically-incident plane $\mathrm{S}$ waves. Because of the characteristics of the structural model and the wave excitation, the vertical and torsional motions are neglected in this study.

\section{SUBSTRUCTURE MODEL}

This problem can be studied using a substructure approach, in which the system is subdivided into building-cap superstructure and soil-foundation stiffness and damping, represented by means of springs and dashpots, as shown in Figure 2. According to Kausel and Roësset [21], the solution can be broken into three steps. In the present case, the first step (kinematic interaction) consists in the determination of the motion of the massless pile cap when subjected to the same input motion as the total solution. Even for vertically-incident harmonic plane $\mathrm{S}$ waves (in which the free-field displacement at the ground surface is exclusively horizontal), this frequency dependent kinematic interaction factors are represented by horizontal $\left(u_{g}\right)$ and rocking $\left(\varphi_{g}\right)$ motions at the pile cap. The next step is to determine the impedances, which are complex-valued frequency-dependent functions $\left(k_{x x}, c_{x x}\right),\left(k_{\theta \theta}, c_{\theta \theta}\right)$ and $\left(k_{x \theta}, c_{x \theta}\right)$ that represent the stiffness and damping of the soil in the horizontal, rocking and cross-coupled horizontal-rocking vibration modes, respectively. The mathematical representation of impedance functions is $K_{i j}=k_{i j}+$ 
$\mathrm{i} a_{o} c_{i j}$, where $a_{o}=\omega b / c_{s}$; being $\omega$ the excitation circular frequency, $c_{s}=\sqrt{\mu_{s} / \rho_{s}}$ the speed of propagation of shear waves in the halfspace, and $\mu_{s}$ and $\rho_{s}$ the soil shear modulus of elasticity and mass density, respectively. Finally, the last step consists in the computation of the response at each frequency of the structure supported on springs and subjected to the motion computed in the first step (see Figure 2a).

$(a)$

(b)

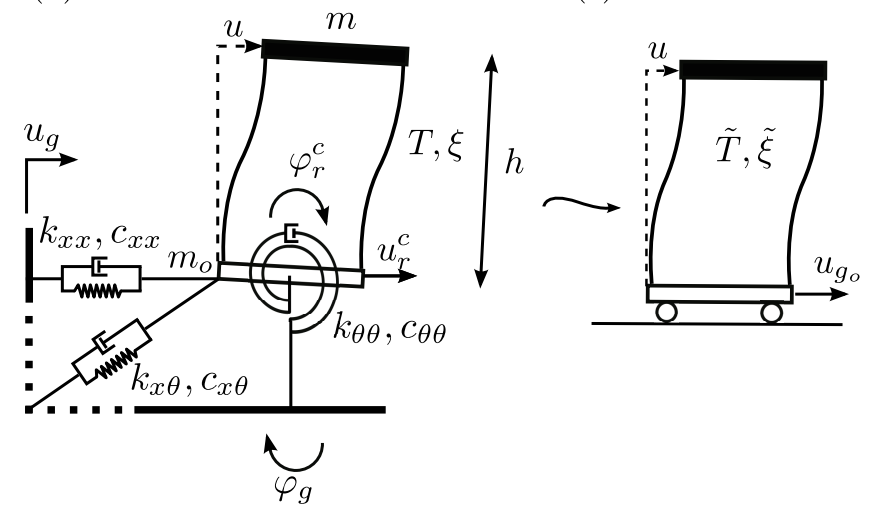

Figure 2: (a) Substructure model of a one-storey structure. (b) Equivalent single-degree-offreedom oscillator

\subsection{Equations of motion}

The equations of motion of the system shown in Figure 2(a), assuming small displacements, can be written in terms of relative motions, $u_{r}^{c}=u^{c}-u_{g}$ and $\varphi_{r}^{c}=\varphi^{c}-\varphi_{g}$, as

$$
\begin{gathered}
m \cdot\left[\ddot{u}+\ddot{u}_{r}^{c}+\ddot{u}_{g}+h\left(\ddot{\varphi}_{g}+\ddot{\varphi}_{r}^{c}\right)\right]+K \cdot u=0 \\
m_{o} \cdot\left[\ddot{u}_{r}^{c}+\ddot{u}_{g}\right]+K_{x x} \cdot u_{r}^{c}+K_{x \theta} \cdot \varphi_{r}^{c}-K \cdot u=0 \\
m \cdot h\left[\ddot{u}+\ddot{u}_{r}^{c}+\ddot{u}_{g}+h\left(\ddot{\varphi}_{g}+\ddot{\varphi}_{r}^{c}\right)\right]+I\left(\ddot{\varphi}_{r}^{c}+\ddot{\varphi}_{g}\right) \\
+K_{\theta x} \cdot u_{r}^{c}+K_{\theta \theta} \cdot \varphi_{r}^{c}+I_{o}\left(\ddot{\varphi}_{r}^{c}+\ddot{\varphi}_{g}\right)=0
\end{gathered}
$$

where eq. (1) represents the horizontal force equilibrium of the vibrating mass, eq. (2) the horizontal force equilibrium of the soil-foundation system and eq. (3) the moment equilibrium of the structure-foundation system about the centre of gravity of the pile cap. In the frequency domain (with time dependance $e^{\mathrm{i} \omega t}$ ), this set of equations can be expressed in a matrix form as

$$
\begin{gathered}
\left\{\left[\begin{array}{ccc}
K & 0 & 0 \\
-K & K_{x x} & K_{x \theta} \\
0 & K_{\theta x} & K_{\theta \theta}
\end{array}\right]-\omega^{2}\left[\begin{array}{ccc}
m & m & m h \\
0 & m_{o} & 0 \\
m h & m h & I_{T}
\end{array}\right]\right\} \\
\cdot\left[\begin{array}{c}
u \\
u_{r}^{c} \\
\varphi_{r}^{c}
\end{array}\right]=\omega^{2}\left\{\left[\begin{array}{c}
m \\
m_{o} \\
m h
\end{array}\right] u_{g}+\left[\begin{array}{c}
m h \\
0 \\
I_{T}
\end{array}\right] \varphi_{g}\right\}
\end{gathered}
$$

where $I_{T}=m h^{2}+I_{o}+I$ and $K=k+\mathrm{i} 2 \omega_{n} m \xi \omega$, being $\omega_{n}=2 \pi / T$ the fixed-base natural frequency of the superstructure. Once the foundation input motion is computed and the righthand vector and the coefficient matrix are known, the structural deflection and foundation relative motions can be computed in the frequency range of interest. 


\subsection{System equations and dimensionless parameters}

A set of dimensionless parameters, covering the main features of SSI problems, has been repeatedly used in the related literature to perform parametric analyses [2, 3, 8, 9]. Following these authors, the parameters that will be used in this paper to characterize the soil-foundationstructure system are: (1) wave parameter $\sigma=c_{s} T / h$ that measures the soil-structure relative stiffness; (2) slenderness ratio $h / b$; (3) mass density ratio $\delta=m /\left(4 \rho_{s} b^{2} h\right)$ between structure and supporting soil; (4) foundation-structure mass ratio $m_{o} / m$; (5) fixed-base structure damping ratio $\xi$; (6) dimensionless fixed-base natural frequency of the structure $\lambda=\omega_{n} / \omega$; (7) dimensionless excitation frequency $a_{o}=\omega b / c_{s}=(b / d)\left(\omega d / c_{s}\right)$; (8) Poisson's ratio $\nu_{s}$ and (9) damping ratio $\xi_{s}$ of the soil. A hysteretic damping model of the type $\mu_{s}=\operatorname{Re}\left[\mu_{s}\right]\left(1+2 \mathrm{i} \xi_{s}\right)$ is considered in this work for the soil material.

Regarding the pile foundation, the following dimensionless parameters are considered: pile spacing ratio $s / d$, embedment ratio $L / b$, pile-soil Young's modulus ratio $E_{p} / E_{s}$, size of the square pile group, dimensionless frequency $a_{o}$, soil-pile densities ratio $\rho_{s} / \rho_{p}$ and pile slenderness ratio $L / d$.

After adding the first two rows so that the second equation represents the horizontal equilibrium of the whole, and performing basic algebraic operations, the equation of motion of the system (4) can be expressed as a function of the dimensionless parameters defined above, as follows

$$
\begin{aligned}
& \left.\left\{\left[\begin{array}{ccc}
\lambda^{2}+2 \lambda \xi \mathrm{i} & 0 & 0 \\
0 & \lambda^{2} \sigma^{2} \frac{1}{16 \pi^{2}} \frac{h}{b} \frac{1}{\delta} \tilde{K}_{x x} & \lambda^{2} \sigma^{2} \frac{1}{\delta} \frac{1}{16 \pi^{2}} \tilde{K}_{x \theta} \\
0 & \lambda^{2} \sigma^{2} \frac{1}{\delta} \frac{1}{16 \pi^{2}} \tilde{K}_{\theta x} & \lambda^{2} \sigma^{2} \frac{1}{16 \pi^{2}} \frac{b}{h} \frac{1}{\delta} \tilde{K}_{\theta \theta}
\end{array}\right]\right\} \begin{array}{c}
\omega_{n}^{2} u / \omega^{2} u_{g_{o}} \\
\omega_{n}^{2} u_{r}^{c} / \omega^{2} u_{g_{o}} \\
\omega_{n}^{2} h \varphi_{r}^{c} / \omega^{2} u_{g_{o}}
\end{array}\right]= \\
& -\left[\begin{array}{ccc}
1 & 1 & 1 \\
1 & 1+\frac{m_{o}}{m} & 1 \\
1 & 1 & 1+\frac{b^{2}}{3 h^{2}}\left(1+\frac{m_{o}}{m}\right)
\end{array}\right] \\
& -\lambda^{2}\left\{\left[\begin{array}{c}
1 \\
1+\frac{m_{o}}{m} \\
1
\end{array}\right] I_{u}+\frac{h}{b}\left[\begin{array}{c}
1 \\
1+\frac{b^{2}}{3 h^{2}}\left(1+\frac{m_{o}}{m}\right)
\end{array}\right] I_{\varphi}\right\}
\end{aligned}
$$

where the rotational inertias have been replaced by the expressions $I=m b^{2} / 3$ and $I_{o}=$ $m_{o} b^{2} / 3$ respectively (pile cap and structure mass uniformly distributed over square areas).

The impedance functions are normalized as follows: $\tilde{K}_{x x}=K_{x x} / \mu_{s} b, \tilde{K}_{\theta \theta}=K_{\theta \theta} / \mu_{s} b^{3}$ and $\tilde{K}_{x \theta}=K_{x \theta} / \mu_{s} b^{2}$, and the kinematic interaction factors are normalized with the free-field motion at the surface $u_{g_{o}}$, being $I_{u}=u_{g} / u_{g_{o}}$ and $I_{\varphi}=\varphi_{g} b / u_{g_{o}}$, both being functions of the dimensionless frequency $a_{o}$.

Equation (5) was validated through comparison against results by Veletsos and Meek [2] for shallow foundations, paper in which impedance functions come from Bielak [7] and Verbic and Veletsos [22]. The validation was completed by reproducing the results obtained by Avilés and Pérez-Rocha [9] for embedded foundations. Negligible differences were obtained in all cases.

\section{EFFECTIVE PERIOD AND DAMPING OF THE COUPLED SYSTEM}

The objective of this section is to find the dynamic characteristics of a viscously damped singledegree-of-freedom (SDOF) oscillator (Figure 2b) able to reproduce, as accurately as possible, the response of the coupled system shown in Figure 2a. This SDOF system can be defined by its undamped natural period $\tilde{T}$ and its damping ratio $\tilde{\xi}$, so that its equation of motion can be 


$$
\frac{\tilde{\omega}_{n}^{2} u}{\omega^{2} u_{g o}}=\frac{1}{\left(\frac{\tilde{\omega}^{2}}{\tilde{\omega}_{n}^{2}}-1\right)-\mathrm{i} 2 \tilde{\xi} \frac{\omega}{\tilde{\omega}_{n}}}
$$

being $\tilde{\omega}_{n}=2 \pi / \tilde{T}$ and $Q=\operatorname{Abs}\left[\omega_{n}^{2} u / \omega^{2} u_{g_{o}}\right]$ the transfer-function used to establish this equivalence, which is the most appropriate from an operational point of view since it represents the ratio of the shear force at the base of the structure to the effective earthquake force [23]. It is not possible to find a SDOF system with constant impedances that exactly reproduces the harmonic response curve of a three-degrees-of-freedom (3DOF) system with either constant or frequencydependent impedances. Therefore, the aim is to reproduce the 3DOF system response within the range where the peak response occurs. As the definition of a SDOF system needs only two parameters, the strategies used to determine its dynamic characteristics are based on taking one common point between the target response of the 3DOF system and that of a SDOF system that best approximates it. To illustrate the different possibilities, Figure 3 shows a schematic representation of the response of the target coupled system (3DOF) together with that of two different extensively used equivalent SDOF models described in previous works of other authors [9, 11], as described along this section. Differences have been exaggerated in the figure to highlight the characteristics of both strategies and show that none of the two approaches reproduces exactly the response of the coupled system, having each one of them its own advantages and disadvantages. From an engineering point of view, the most intuitive strategy consist in taking as common point the one corresponding to the maximum value $Q_{m}$ of the response spectra (see MAX in Figure 3) as some authors such as Todorovska [11] or Avilés and Pérez-Rocha [9] do. This strategy $(\mathrm{MAX})$ can be attained in this case by the iterative resolution of the system of equations (5), allowing to find the peak-response period $T_{m}$ and the corresponding maximum value $Q_{m}$. Then, assuming that the damping mechanism of the equivalent SDOF oscillator is of viscous nature, it is well-known that its damping ratio can be found as

$$
\tilde{\xi}=\frac{1}{\sqrt{2}}\left(1-\sqrt{\frac{Q_{m}^{2}-1}{Q_{m}^{2}}}\right)^{\frac{1}{2}}
$$

which is obtained from the expression for $Q_{m}$ in Figure 3. Now, the natural period of the equivalent oscillator $\tilde{T}$ can be computed as

$$
\tilde{T}=\sqrt{1-2 \tilde{\xi}^{2}} T_{m}
$$

which is applicable only for damping values smaller than $1 / \sqrt{2}$ [24].

Nevertheless, this strategy leads to unreliable natural frequencies in highly damped systems, in which the peak-response frequency becomes rather undefined. In order to avoid this drawback, other approach based on finding the eigenvalue $\tilde{\lambda}$ of the $3 \mathrm{DOF}$ system can be used. In this respect, it is highly illustrative the procedure proposed on this line by Avilés and Pérez-Rocha [9] for embedded foundations starting from analogous equations to those presented herein. These authors adopt a simplification which consist in neglecting the cross-coupled horizontal-rocking terms and then also the high-order terms involving products of damping coefficients in the resulting expressions. By doing so, they obtain manageable approximated expressions for the period and damping of the interacting system. Such assumption has been extensively used by many authors $[1,2,3,7,4,5,25,6,8]$. However, neglecting the cross-coupled stiffness and damping terms $k_{x \theta}$ and $c_{x \theta}$ is not acceptable for pile foundations, not even for certain configurations of embedded foundations. Therefore, in order to obtain equivalent equations while keeping the crossed-coupled impedances, it is necessary to condense the soil-foundation interaction to a point at a certain virtual depth $D(\omega)=-K_{x \theta} / K_{x x}$ (see Figure 4 ) such that 


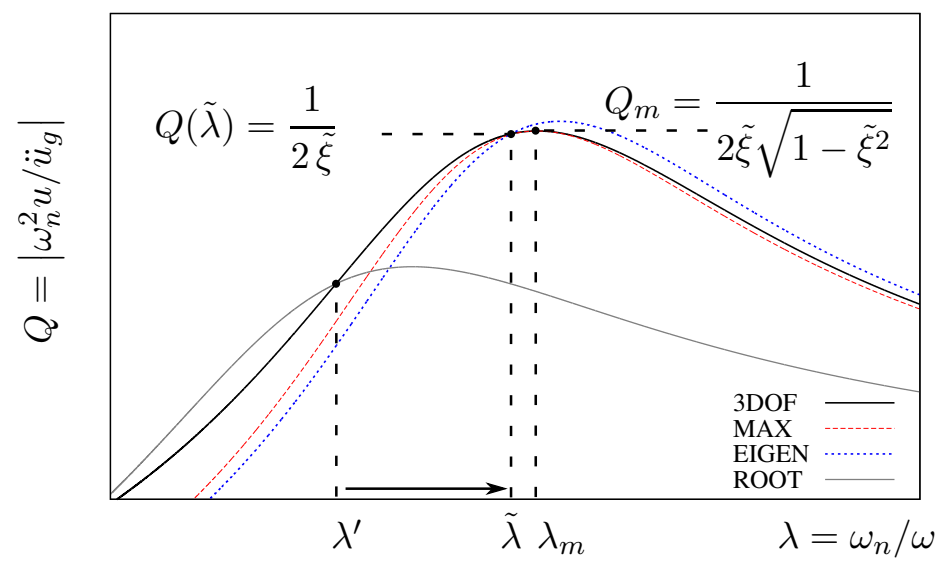

Figure 3: Strategies for obtaining the natural frequency and damping of the equivalent SDOF system

the impedance matrix becomes diagonal, as some authors propose $[26,18]$. If, in addition, $m_{o}$, $I$ and $I_{o}$ are neglected as usual (see, for instance [9]), eq. (5) becomes

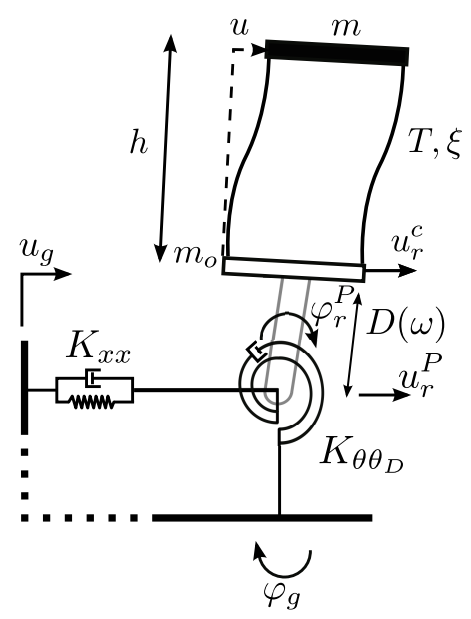

Figure 4: Equivalent model with diagonalized impedance matrix

$$
\begin{aligned}
& \left\{\lambda^{2}\left[\begin{array}{ccc}
\left(1+\mathrm{i} 2 \xi^{\prime}\right) & 0 & 0 \\
0 & \alpha_{x x}^{2}\left(1+\mathrm{i} 2 \xi_{x x}\right) & 0 \\
0 & 0 & \alpha_{\theta \theta}^{2}\left(1+\mathrm{i} 2 \xi_{\theta \theta}\right)
\end{array}\right]-\right. \\
& \left.\left[\begin{array}{lll}
1 & 1 & 1 \\
1 & 1 & 1 \\
1 & 1 & 1
\end{array}\right]\right\} \cdot\left[\begin{array}{c}
\omega_{n}^{2} u / \omega^{2} u_{g_{o}} \\
\omega_{n}^{2} u_{r}^{P} / \omega^{2} u_{g_{o}} \\
\omega_{n}^{2}(h+D) \varphi_{r}^{c} / \omega^{2} u_{g_{o}}
\end{array}\right]=-\lambda^{2}\left(I_{u}+\frac{h}{b} I_{\varphi}\right)\left[\begin{array}{l}
1 \\
1 \\
1
\end{array}\right]
\end{aligned}
$$

where,

$$
\begin{gathered}
\xi^{\prime}=\frac{\omega}{\omega_{n}} \xi \\
\alpha_{x x}^{2}=\sigma^{2} \frac{1}{16 \pi^{2}} \frac{h}{b} \frac{1}{\delta} \tilde{k}_{x x} \\
\xi_{x x}=\frac{\tilde{c}_{x x}}{2 \tilde{k_{x x}}}
\end{gathered}
$$




$$
\begin{gathered}
\alpha_{\theta \theta}^{2}=\sigma^{2} \frac{1}{16 \pi^{2}} \frac{h}{b} \frac{1}{\delta} \operatorname{Re}\left[\frac{b^{2}}{(h+D)^{2}} \tilde{K}_{\theta \theta_{D}}\right] \\
\xi_{\theta \theta}=\frac{\operatorname{Im}\left[\frac{b^{2}}{(h+D)^{2}} \tilde{K}_{\theta \theta_{D}}\right]}{2 \operatorname{Re}\left[\frac{b^{2}}{(h+D)^{2}} \tilde{K}_{\theta \theta_{D}}\right]}
\end{gathered}
$$

being $\tilde{K}_{x x}=\tilde{k}_{x x}+\mathrm{i} \tilde{c}_{x x}$ and

$$
\begin{gathered}
\tilde{K}_{\theta \theta_{D}}=\frac{1}{\mu_{s} b^{3}}\left(K_{\theta \theta}-\frac{K_{\theta x}^{2}}{K_{x x}}\right) \\
\frac{b^{2}}{(h+D)^{2}}=\left(\left(\frac{h}{b}\right)^{2}-2\left(\frac{h}{b}\right) \frac{\tilde{K}_{\theta x}}{\tilde{K}_{x x}}+\left(\frac{\tilde{K}_{\theta x}}{\tilde{K}_{x x}}\right)^{2}\right)^{-1}
\end{gathered}
$$

Solving the complex system of algebraic equations given in (9) for $\omega_{n}^{2} u / \ddot{u}_{g_{o}}$ yields the following expression for $Q$

$$
Q(\lambda)=\left|\frac{I_{u}(\lambda)+\frac{h}{b} I_{\varphi}(\lambda)}{A(\lambda)+\mathrm{i} B(\lambda)}\right|
$$

where

$$
\begin{aligned}
& A(\lambda)=1-\frac{1}{\lambda^{2}}-\frac{1+4 \xi_{x x} \xi^{\prime}}{\lambda^{2} \alpha_{x x}^{2}\left(1+4 \xi_{x x}^{2}\right)}-\frac{1+4 \xi_{\theta \theta} \xi^{\prime}}{\lambda^{2} \alpha_{\theta \theta}^{2}\left(1+4 \xi_{\theta \theta}^{2}\right)} \\
& B(\lambda)=2\left[\xi^{\prime}-\frac{\xi^{\prime}-\xi_{x x}}{\lambda^{2} \alpha_{x x}^{2}\left(1+4 \xi_{x x}^{2}\right)}-\frac{\xi^{\prime}-\xi_{\theta \theta}}{\lambda^{2} \alpha_{\theta \theta}^{2}\left(1+4 \xi_{\theta \theta}^{2}\right)}\right]
\end{aligned}
$$

The identification of the equations of motion of the coupled system $(17,18,19)$ and that corresponding to the SDOF system (6) at resonance allows to obtain the effective period by finding the root of equation (18). Obviously, the 3DOF system has more than one vibration mode and hence equation (18) has more than one root. However, in most cases of interest, the maximum response corresponds to the first mode. For this reason, from now on, the procedure focuses on that first solution $\lambda^{\prime}$, despite being aware that there are more. Thus, the system damping ratio can be determined as $\tilde{\xi}=1 /\left(2 Q\left(\lambda^{\prime}\right)\right)$.

Note that using the root $\lambda^{\prime}$ of equation (18) leads to a SDOF system whose peak response does not always lead to an acceptable approximation for the 3DOF system peak response (see ROOT in Figure 3). However, better results are obtained by neglecting (as Avilés and Pérez-Rocha [9] do) all second-order damping terms, which leads to the following approximate expressions for $A$ and $B$ :

$$
\begin{gathered}
A(\lambda)=1-\frac{1}{\lambda^{2}}-\frac{1}{\lambda^{2} \alpha_{x x}^{2}}-\frac{1}{\lambda^{2} \alpha_{\theta \theta}^{2}} \\
B(\lambda)=2\left[\xi^{\prime}-\frac{\xi^{\prime}-\xi_{x x}}{\lambda^{2} \alpha_{x x}^{2}}-\frac{\xi^{\prime}-\xi_{\theta \theta}}{\lambda^{2} \alpha_{\theta \theta}^{2}}\right]
\end{gathered}
$$

The dimensionless undamped natural frequency of the SDOF system $\tilde{\lambda}=\omega_{n} / \tilde{\omega}_{n}$ can be found as the root of the equation (20). This is equivalent to the resolution of the eigenvalue problem from equation (9), without considering damping. 
As, in this case, $\tilde{\xi}=1 /(2 Q(\tilde{\lambda}))$, and taking the approximate expression for $Q(\tilde{\lambda})$ obtained from taking equations (20) and (21) as values of $A$ and $B$, one can write the system damping ratio as

$$
\tilde{\xi}=\left|\left(I_{u}+\frac{h}{b} I_{\varphi}\right)^{-1} \frac{1}{\tilde{\lambda}^{2}}\left(\xi^{\prime}+\frac{\xi_{x x}}{\alpha_{x x}^{2}}+\frac{\xi_{\theta \theta}}{\alpha_{\theta \theta}^{2}}\right)\right|
$$

However, it should be noticed that the influence of neglecting all second-order terms increases with decreasing values of the pile slenderness ratio $L / d$, the structural slenderness ratio $h / b$ and the wave parameter $\sigma$ as well as with increasing values of the embedment ratio $L / b$ and the group size. Indeed, this assumption may lead to significant differences on the system period and damping values when $h / b \leq 2$. Therefore, and unlike what Avilés and Pérez-Rocha [9] do, the proposed procedure (EIGEN in Figure 3) calculates $\tilde{\xi}$ from equations (18) and (19) for the values of $A$ and $B$ instead of equations (20) and (21), which yields the following expression

$$
\tilde{\xi}=\left|\left(I_{u}+\frac{h}{b} I_{\varphi}\right)^{-1}\left[\frac{\xi^{\prime}}{\tilde{\lambda}^{2}}+\frac{1}{\tilde{\lambda}^{2}}\left(\frac{\xi_{x x}}{\alpha_{x x}^{2}\left(1+\mathrm{i} 2 \xi_{x x}\right)}+\frac{\xi_{\theta \theta}}{\alpha_{\theta \theta}^{2}\left(1+\mathrm{i} 2 \xi_{\theta \theta}\right)}\right)\right]\right|
$$

When $\tilde{\xi}<0.2$, effective period and damping results obtained either from this last described root finding procedure (EIGEN), or by the iterative solution of the system of equations given in (5) to find the maximum response value (MAX), are almost coincident. Figure 5 illustrates this fact for one particular case. However, although both procedures lead to good results in most cases, it is important to point out that, contrary to what occurs with the maximum searching algorithm (MAX), the root finding procedure (EIGEN) will show, in all cases, a stable behaviour whose reliability is not affected by increasing values of the equivalent system damping $(\tilde{\xi}>0.2)$. For this reason, the simplified procedure (EIGEN) is the strategy employed forward, being also true that, as discussed below, the equivalent SDOF system is not always applicable as a simplified methodology for highly damped systems.
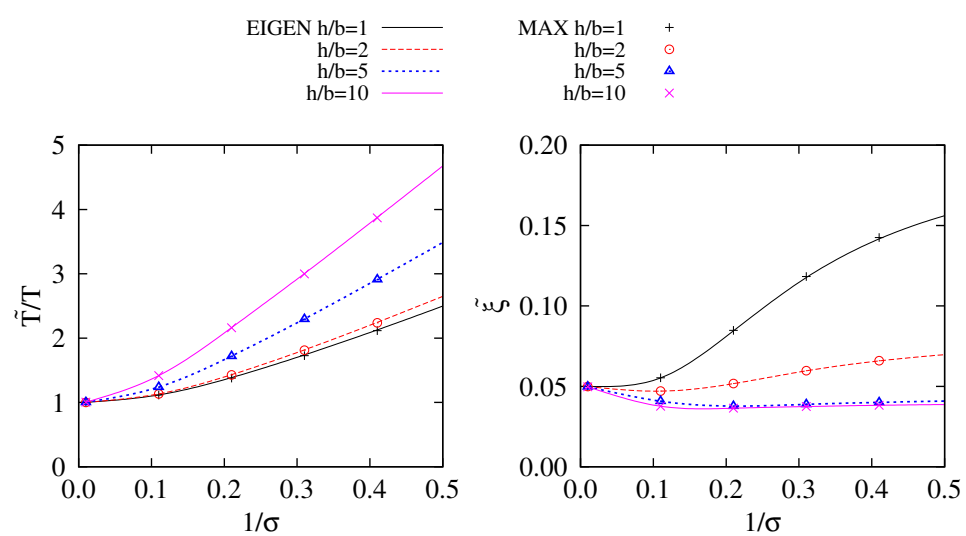

Figure 5: Root finding procedure (EIGEN) vs maximum searching algorithm (MAX). Natural period $\tilde{T} / T$ and damping ratio $\tilde{\xi}$ for a $2 \times 2$ pile group. Ep $/ E s=10^{3}, s / d=15, h / b=2,5,10$, $L / b=2, L / d=30$ and $\xi_{s}=0.05$.

Finally, after having described the numerical procedure to be used for defining the parameters of the equivalent single-degree-of-freedom system, and keeping in mind that the response of such SDOF replacement oscillator does not match exactly that of the complete 3DOF system, it is 

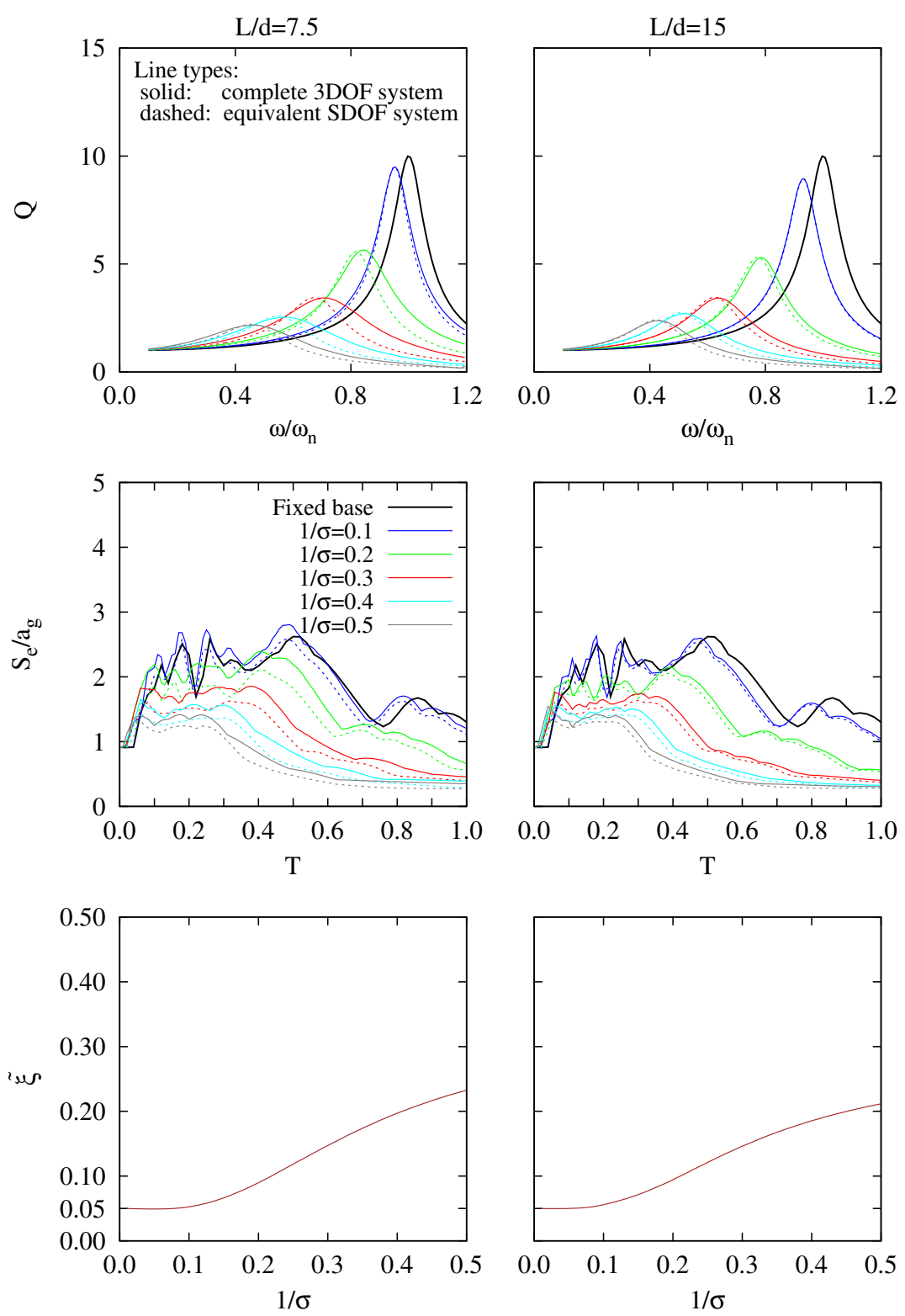

Figure 6: Replacement oscillator approach to $3 D O F$ system on a $2 \times 2$ pile group. $L / b=1$, $L / d=7.5$ (left columns) and $L / d=15$ (right column). Transfer functions (top), Elastic response spectra corresponding to the 1940 El Centro Earthquake (middle), and damping ratio $(\tilde{\xi})$ of the equivalent SDOF replacement oscillator (bottom). 
necessary to establish a practical range of validity which, as generally assumed, will depend on the problem characteristics. Avilés and Suárez [13] drew the conclusion that the equivalent SDOF approach is not adequate for highly damped systems $(\tilde{\xi}>0.2)$, which usually corresponds to very short structures $(h / b \leq 1)$ on soft soils $(1 / \sigma>0.2)$. The results obtained for a significant number of the configurations analyzed in the present paper agree with such conclusion and suggest a limit value of the parameter $1 / \sigma$ between 0.2 and 0.3 , depending on the configuration. However, in many other cases, the replacement SDOF oscillator yields excellent results even for high damping ratios $(\tilde{\xi}>0.2)$. On the other hand, the pile group configuration is another important parameter in the range of validity of the approach. In order to illustrate this fact, Figure 6 presents frequency response functions and elastic response spectra (corresponding to the N-S component of the 1940 El Centro Earthquake [23]) both obtained keeping 1/ $\sigma$ constant as in [2], for the case of a $2 \times 2$ pile group with embedment and slenderness ratios of $L / b=2$ and $L / d=7.5$ and 15 , respectively. In both cases, for $h / b=1$, the equivalent damping ratio $\tilde{\xi}$ is very similar (see bottom plots in the same figure). However, while the SDOF replacement oscillator is able to approximate very closely the frequency response functions of the complete system when $L / d=15$, the same does not hold when $L / d=7.5$. As a consequence, the elastic response spectra obtained from the equivalent SDOF system are very close to those obtained using the response of the complete $3 \mathrm{DOF}$ system for $L / d=15$ and all values of $1 / \sigma$. However, discrepancies are very important for $L / d=7.5$, even for $1 / \sigma=0.1$. Therefore, it is important to point out that the equivalent single-degree-of-freedom approach shows a finite range of validity that should be take into account before its practical application.

\section{RESULTS}

The procedure proposed above is used in this section to study the influence of SSI on the response of pile-supported structures in terms of the maximum shear force at the base of the structure per effective earthquake force unit $Q_{m}$, and the effective system period $\tilde{T} / T$ and damping $\tilde{\xi}$. The foundation horizontal displacement $\left|\omega_{n}^{2} u_{r}^{c} / \ddot{u}_{g_{o}}\right|$ and rocking $\left|\omega_{n}^{2} h \varphi_{r}^{c} / \ddot{u}_{g_{o}}\right|$, or the kinematic interaction factor $\left|I_{u}+(h / b) I_{\varphi}\right|$ will also be shown in different cases. Even though it is not a comprehensive analysis, several interesting conclusions can be drawn from studing how the SSI effects on the system dynamic behaviour are influenced by the variation of parameters such as the structural slenderness ratio $h / b$, the wave parameter $\sigma$, the spacing between adjacent piles $s / d$, the embedment ratio $L / b$ and the number of piles.

Also, different pile group configurations, for which the values of the dimensionless parameters are listed in Table 1, are analysed in the frequency range of interest for seismic loading $\left(\omega d / c_{s}<\right.$ 0.5, according to Gazetas et al. [27]). All configurations follow the pattern represented in Figure 7.

Table 1: Pile groups configurations

\begin{tabular}{ccccc}
\hline \multirow{2}{*}{$L / b$} & \multirow{2}{*}{$L / d$} & \multicolumn{3}{c}{$s / d$} \\
\cline { 3 - 5 } & & $2 \times 2$ & $3 \times 3$ & $4 \times 4$ \\
\hline \multirow{2}{*}{1} & 7.5 & 7.5 & 5 & 3.75 \\
& 15 & 15 & 10 & 7.5 \\
\hline \multirow{2}{*}{2} & 7.5 & 3.75 & 2.5 & 1.875 \\
& 15 & 7.5 & 5 & 3.75 \\
& 30 & 15 & 10 & 7.5 \\
\hline \multirow{2}{*}{4} & 15 & 3.75 & 2.5 & 1.875 \\
& 30 & 7.5 & 5 & 3.75 \\
\hline
\end{tabular}

It is assumed that $\delta=0.15 ; m_{o} / m=0 ; 0<1 / \sigma<0.5 ; h / b=1,2,5,10 ; \xi=0.05 ; \xi_{s}=0.05$ and $\nu_{s}=0.4$. These values are representative for typical buildings and soils [9]. Moreover, 


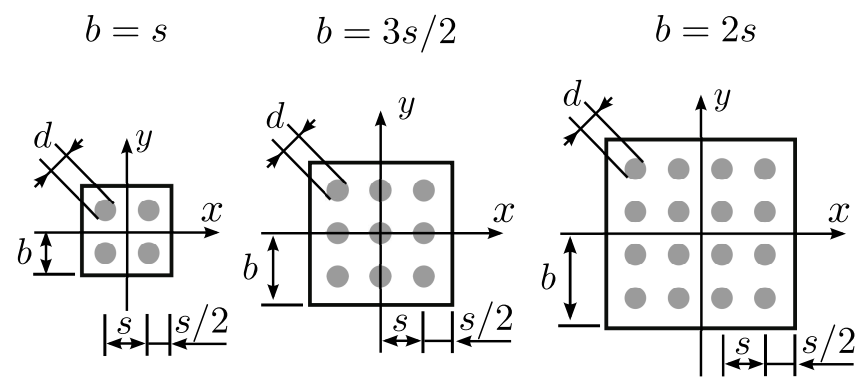

Figure 7: Geometric configuration of groups of $2 \times 2,3 \times 3$ and $4 \times 4$ piles

$E_{p} / E_{s}=10^{3}$ and $\rho_{s} / \rho_{p}=0.7$.

It has been verified that the variation of the parameter $m_{o} / m$ in the range between 0 and 0.5 does not yield significant differences in terms of $Q_{m}, \tilde{T} / T$ and $\tilde{\xi}$ or the foundation horizontal displacement $\left|\omega_{n}^{2} u_{r}^{c} / \ddot{u}_{g_{o}}\right|$ and rocking $\left|\omega_{n}^{2} h \varphi_{r}^{c} / \ddot{u}_{g_{o}}\right|$. These conclusions support the simplification usually assumed by neglecting $m_{o}$ which is necessary to obtain the dimensionless expressions of the solution procedure proposed in this paper.

The range of values used in this study for $1 / \sigma$ encompasses most real cases as can be seen in Stewart et al. [28], where empirical results for SSI effects are provided for 57 building sites that covers a wide range of real structural and geotechnical conditions. Most of these cases show values of $1 / \sigma$ between 0 and 0.3 .

With regard to the mass density ratio between structure and supporting soil $\delta$, it should be metioned that this parameter has a relevant influence on the system reponse. Figure 8 shows that the decrease of $\delta$ implies an increase of the system stiffness which leads to lower values of effective period $\tilde{T} / T$ and damping $\tilde{\xi}$ and, consequently, higher values of $Q_{m}$. The effects associated to SSI become more remarkable as the structural slenderness ratio $h / b$ increases. Nevertheless, as metioned before, the value considered herein $(\delta=0.15)$ is representative for typical buildings and soils and has been used in previous works by other authors such as Avilés and Pérez-Rocha [9] or Veletsos and Meek [2].

\subsection{Impedances and kinematic interaction factors}

Impedances and kinematic interaction factors are key and non-trivial aspects of the problem. Different expressions and graphs are available in the literature for certain configurations. However, in general, obtaining accurate values for a particular case requires the use of sophisticated numerical models allowing to incorporate foundation-soil interaction rigorously. A large number of works address the computation of impedance functions (dynamic stiffness) of piles and pile groups. For example, analytical expressions for single floating piles are reported by Gazetas [29], while Dobry and Gazetas [30] present expressions for pile groups using group factors that are an extension of those obtained for static problems by Poulos [31]. Other researches related to impedance expressions have been carried out by Konagai et al. [32], Taherzadeh et al. [33] or Dai and Roësset [34]. In regard to kinematic interaction factors for piled foundations, and with respect to numerical research, several studies have also been carried out (see, for instance, $[35,36,27,37,38])$.

In this paper, all impedance functions and kinematic interaction factors are computed using a boundary element (BEM)- finite element (FEM) coupling model [39, 40, 41]. Piles are modelled directly using FEM as beams according to the Bernoulli hypothesis, while soil is modelled using BEM as a linear, isotropic, homogeneous, viscoelastic medium. Welded boundary contact conditions at the pile-soil interfaces are assumed and the pile heads are constrained by a rigid pile-cap which is not in contact with the half-space. This model for piled foundations is along the lines of those proposed by other authors $[38,42,16]$. For more details on the BEM formulation, it is really interesting to consult Manolis and Beskos [43] and Domínguez [44], two reference 

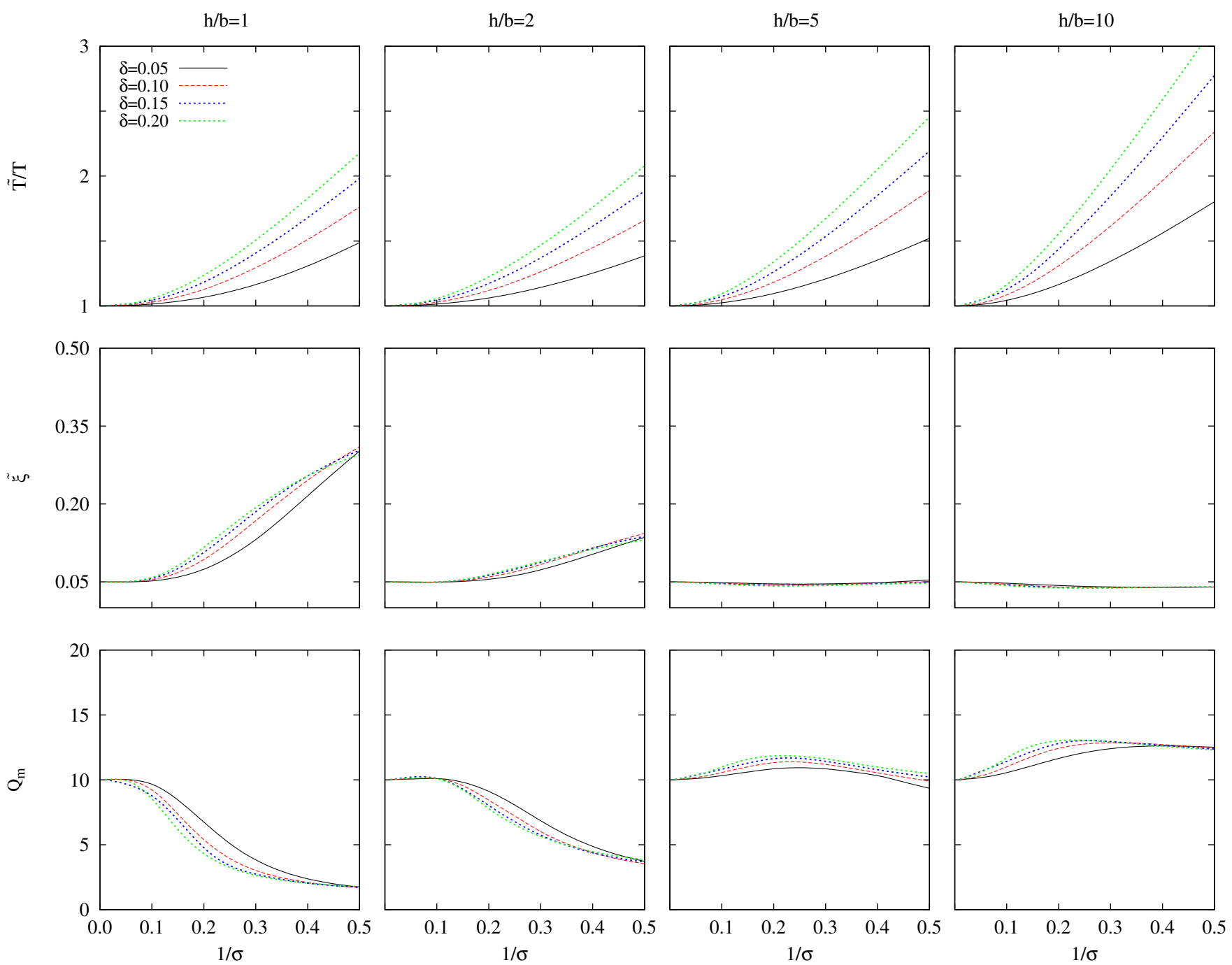

Figure 8: Effective period $\tilde{T} / T$, damping ratio $\tilde{\xi}$ and maximum structural response value $Q_{m}$ for a $3 \times 3$ pile group with $L / d=15, L / b=2, E p / E s=10^{3}$ and $\xi_{s}=0.05$. Influence of the mass density ratio between structure and supporting soil $\delta$ 

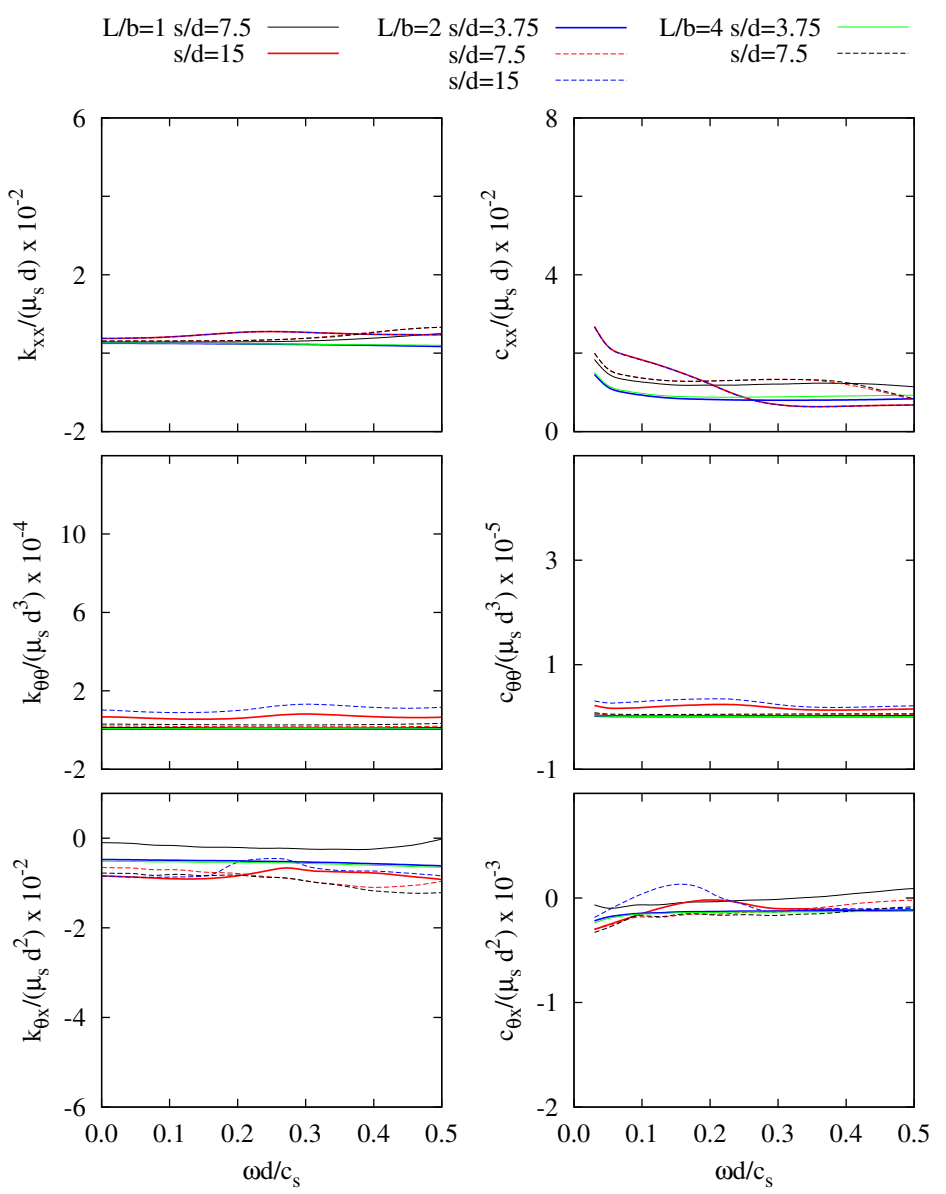

Figure 9: Impedance functions of different $2 \times 2$ pile groups; $E_{p} / E_{s}=10^{3}$ and $\xi_{s}=0.05$.

works on the subject.

Figures 9 to 11 show the impedances of the pile groups under investigation in the range of $a_{o}$ needed to obtain all results presented in the next sections. On the other hand, Figure 12 presents their kinematic interaction factors in terms of an idealized general shape [27] for each $L / d$. This shape is the midline of a band which contains all the curves obtained for the different configurations studied with this value of $L / d$. It has been shown that the kinematic interaction factor associated with translation $I_{u}$ depends mainly on $L / d$ and it is not significantly influenced by the group size. However, this conclusion is not so valid for $I_{\varphi}[36,27,45]$. By using the idealized kinematic interaction functions for a given value of $L / d$ (see Figure 12), the mean relative error committed in terms of $Q_{m}$, taking as a reference the response obtained with their exact values, is always lower than $14 \%$ for all these cases. It should be noted that, this effect decreases for increasing values of $h / b$. Thus, when $h / b=10$ the relative error reaches a $4 \%$ for the most unfavourable configuration. However, although only the idealized shape of $I_{u}$ and $I_{\varphi}$ for each value of $L / d$ is presented for the sake of brevity, all results presented in section 5 have been obtained with the exact kinematic interaction functions.

\subsection{Influence of cross-coupled impedances}

All the results presented in this paper are obtained considering all the elements of the matrix of impedances. Although many authors neglect the cross-coupled stiffness and damping terms $[2,7$, $8,3]$, this is not acceptable for pile foundations, not even for certain configurations of embedded foundations. Therefore, a comparative analysis to determine the influence of the cross-coupled impedances on the system dynamic response has been addressed (not shown for the sake of brevity). This influence generally increase with $L / b$ and the size of the pile group. However, it 


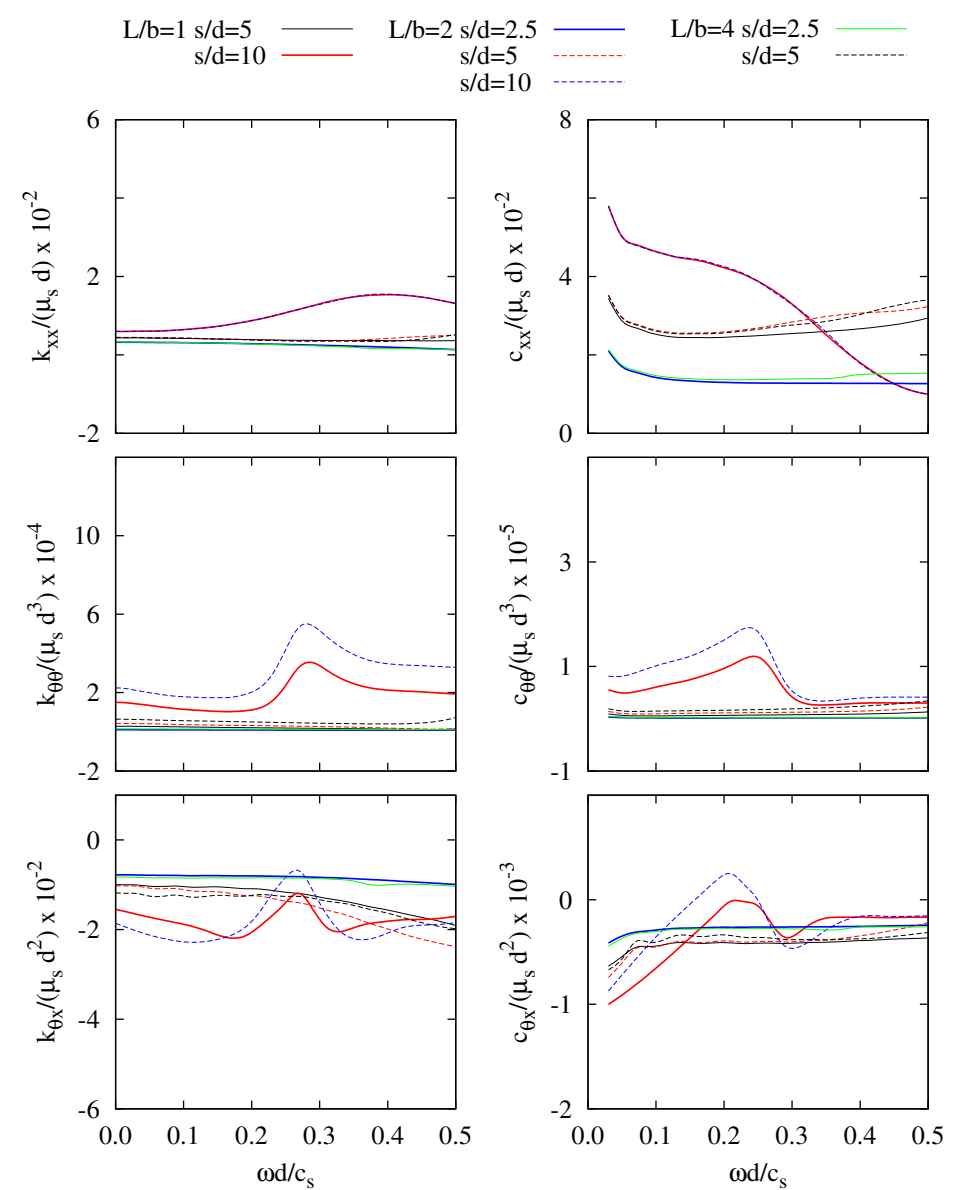

Figure 10: Impedance functions of different $3 \times 3$ pile groups; $E_{p} / E_{s}=10^{3}$ and $\xi_{s}=0.05$. 

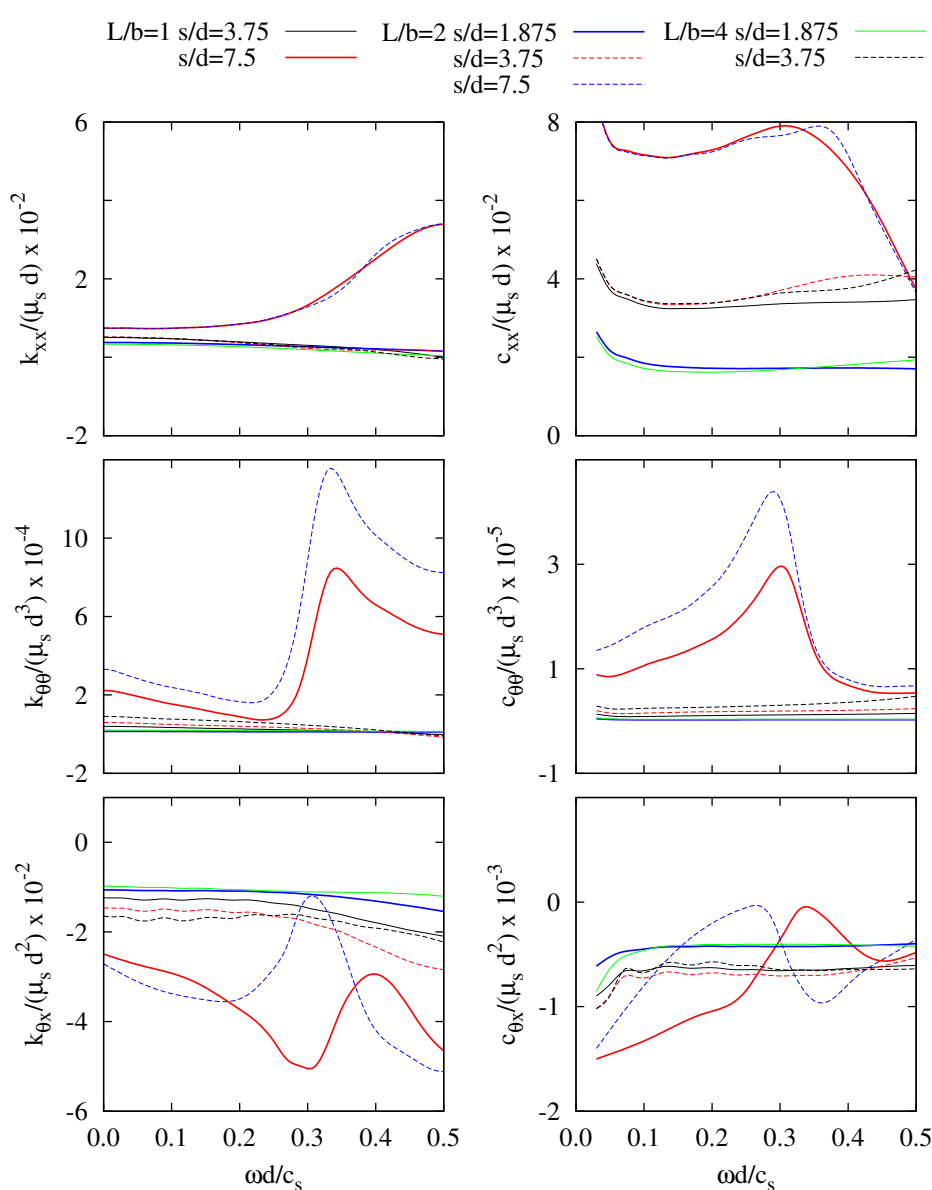

Figure 11: Impedance functions of different $4 \times 4$ pile groups; $E_{p} / E_{s}=10^{3}$ and $\xi_{s}=0.05$.
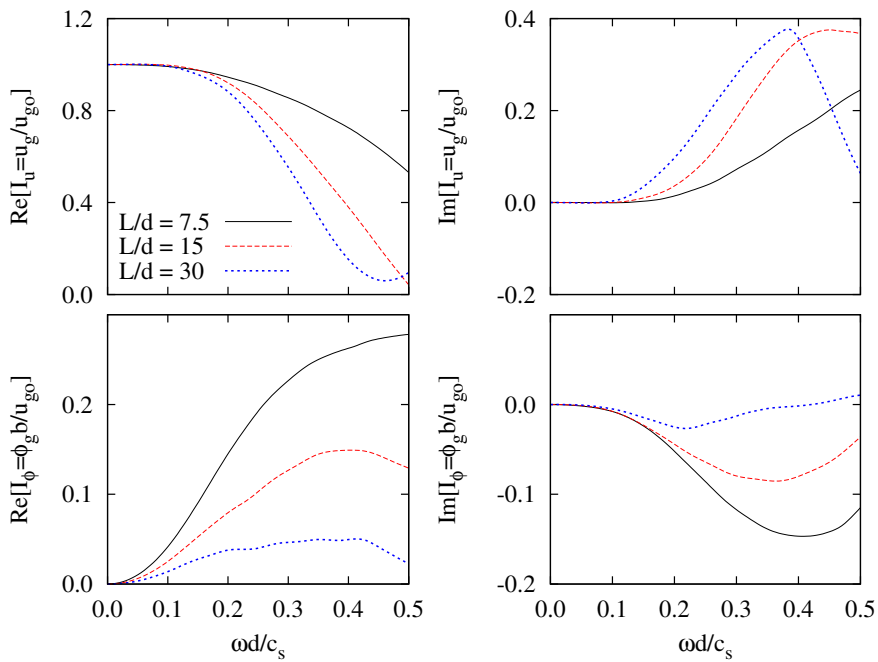

Figure 12: Kinematic interaction factors of different pile groups embedded in a soil with $E_{p} / E_{s}=10^{3}$ and $\xi_{s}=0.05$. 
decreases with increasing values of $\sigma, h / b$ or $L / d$.

In a significant number of cases, the system damping $\tilde{\xi}$ decreases when considering the crosscoupled impedances, which implies that the system dynamic response is subestimated when neglecting them. On the other hand, the system natural period $\tilde{T}$ increases in all cases when the cross-coupled impedances are taken into account.

In the configurations studied in this work, the relative error in terms of $Q_{m}$, committed by neglecting the cross-coupled impedances, reaches a maximum value of $40 \%$. However, the mean relative error is below $16 \%$.

\subsection{Influence of the structural slenderness ratio $h / b$ and the wave parameter $\sigma$ on the system dynamic behaviour}

The influence of the structural slenderness ratio $h / b$ and the wave parameter $\sigma$ is examined from Figures 13 to 16 . Figures 14 to 16 will also be used for comparative analysis in next subsections. First, figure 13 shows the system effective periodo $\tilde{T} / T$ for structures with $h / b=1,2,5$ and 10 , and several pile configurations. As expected, the system effective period $\tilde{T} / T$ increases for decreasing values of $\sigma$, which implies lower soil stiffness. Generally, lower values of $h / b$ lead to a reduction of $\tilde{T} / T$. However, this trend can change for $h / b \leq 1$ (see Figure 13). In all cases, SSI implies an increase of the system period $(\tilde{T}>T)$. On the contrary, the value of the effective damping ratio $\tilde{\xi}$ can be greater or lower than that corresponding to the fixed-base structure depending mainly on $h / b$ (see figures 14,15 or 16). For buildings with $h / b<5$, it increases with $1 / \sigma$ and shows values over the fixed-base structural damping ratio. By contrast, for buildings with $h / b \geq 5$ it is almost independent of $1 / \sigma$ so it stands at around the fixed-base structural damping ratio. Similar conclusions have been extracted from studies in the same line for structures founded on shallow [2] and embedded foundations [9].

Again from figures 14, 15 or 16, it should be noted that, for short and squat buildings with $h / b \leq 2$, the value of $Q_{m}$ decreases as $1 / \sigma$ increases. However, for high buildings with $h / b \geq 3$, $Q_{m}$ is moderately dependent on $1 / \sigma$ and it can reach values over that corresponding to fixedbase condition. Furthermore, the maximum value of $Q_{m}$ occurs for greater values of $1 / \sigma$ (in most cases between 0.1 and 0.3 ), as $h / b$ increases. Indeed, in the cases analysed in this paper, the maximum value obtained for $Q_{m}$ when considering SSI effects is $67 \%$ greater than that corresponding to fixed-base condition.

The foundation horizontal displacement $\left|\omega_{n}^{2} u_{r}^{c} / \ddot{u}_{g_{o}}\right|$ (see figures 15 and 16) increases with $1 / \sigma$ for all cases under study. Its dependence on the structural slenderness ratio $h / b$ is related with the configuration corresponding to each particular case. Besides, the foundation rocking $\left|\omega_{n}^{2} h \varphi_{r}^{c} / \ddot{u}_{g_{o}}\right|$ increases with $1 / \sigma$ being this effect more pronounced for greater values of the ratio $h / b$.

\subsection{Influence of kinematic interaction factors}

Figure 14 allows to show the extent to which kinematic interaction influences the dynamic characteristics of the system. To this end, this figure presents $\tilde{T}, \tilde{\xi}$ and $Q_{m}$ functions involving total soil-structure interaction (both kinematic and inertial interaction) or only inertial interaction for different pile groups $(2 \times 2,3 \times 3$ and $4 \times 4)$ with the same pile slenderness $(L / d)$ and mechanical properties $\left(E_{p} / E_{s}\right)$. Kinematic interaction is also assessed in this case through the function $\left|I_{u}+(h / b) I_{\varphi}\right|$. Obviously, as the natural frequency of any system does not depend on the excitation, the system effective period is insensitive to kinematic interaction. However, in most cases, the effective damping decreases when these factors are taken into account $\left(\left|I_{u}+(h / b) I_{\varphi}\right|>1\right)$. On the contrary, this trend could be reversed for non-slender structures $(h / b \leq 1)$ on soft soils $(1 / \sigma \geq 0.2)$ (i.e. $\left.\left|I_{u}+(h / b) I_{\varphi}\right|<1\right)$. This effect becomes more noticeable as the group size increases (stiffer foundation). Consequently, the results obtained without considering the kinematic interaction effects are not on the side of safety except for those corresponding to nonslender structures $h / b \leq 1$. Similar conclusions were drawn by Avilés and Pérez-Rocha [9] for 
embedded foundations.

It should be noted that, for those cases where the kinematic interaction effects are relevant, their influence becomes more noticeable as the wave parameter $\sigma$ decreases. With respect to the damping ratio, the influence of the kinematic interaction effects decreases and even disappears for decreasing values of foundation stiffness, and the same happens for increasing values of the slenderness ratio of the structure $h / b$.

The relative error, in terms of maximum shear force at the base of the structure $Q_{m}$, committed by ignoring the kinematic interaction factors, reaches a $55 \%$ for the most unfavourable configuration of those analysed. This occurs for non-slender structures $h / b=1$ in which the maximum structural response value is below that corresponding to the fixed-base condition. However, the relative error is below $10 \%$ for buildings with $h / b=10$.

\subsection{Influence of pile group size}

As shown in Figure 14, for piled foundations with high $h / b$ and the same embedment ratio $L / b$ and pile slenderness ratio $L / d$, fewer piles lead to a reduction of the system stiffness, which results in an increase of the effective period. However, the magnitude of this trend decreases for decreasing values of $h / b$, and tends to be the opposite for non-slender structures. On the other hand, a larger pile group leads to greater values of the system effective damping and, consequently, smaller maxima $Q_{m}$ in the response, when $h / b<5$, while no clear trends are observed for higher slendernesses. For high buildings $(h / b=5$ and 10$)$ the value obtained for $Q_{m}$ when considering SSI exceeds that corresponding to fixed-base condition. Also, the maximum value of $Q_{m}$ occurs for $1 / \sigma=0.2$ when $h / b=5$ and increases with $1 / \sigma$ for $h / b=10$, approaching (in the depicted range) an asymptotic value that increases with the number of piles.

Regarding the foundation horizontal displacement and rocking, both increase for smaller pile groups, being this effect more remarkable for slender structures (results not shown).

\subsection{Influence of the pile slenderness ratio $L / d$}

As shown in Figure 15, for piled foundations with the same embedment ratio $L / b$, increasing values of $L / d$ (more slender piles) imply a reduction of the effective length of piles, and consequently a diminution of the system stiffness, which results in an increase of the effective period. This effect increases as the soil stiffness decreases (lower values of $\sigma$ ). These differences are smaller for short and squat structures (lower values of $h / b$ ); although this trend is even reversed for very low values of this parameter (results not shown). By contrast, in regard to the damping ratio, generally, the increase of $L / d$ reduces the system damping. This effect becomes less appreciable for slender structures (greater values of $h / b$ ). It should be noted that for $h / b \geq 5$ the system damping $\tilde{\xi}$ is close to the structural damping $\xi$ and it is not too sensitive to $L / d$ variations. Furthermore, it can be seen that there are not significant differences between the results for the damping ratio for $L / d=7.5$ and $L / d=15$, respectively.

The results for the system maximum response $Q_{m}$ are affected by the trends explained above regarding the damping ratio $\tilde{\xi}$. Thus, it should be noticed that when $h / b \leq 2, Q_{m}$ reaches greater values for $L / d=30$ than for lower values of $L / d$; and there are not significant differences between the results obtained for $L / d=7.5$ and $L / d=15$, respectively. However, a change of trend can be observed when $h / b \geq 5$.

Concerning the foundation horizontal displacement and rocking, it can be seen that both increase for greater values of the pile slenderness ratio $L / d$.

\subsection{Influence of the embedment ratio $L / b$}

As shown in Figure 16, for piled foundations with the same spacing between adjacent piles $s / d$, keeping the foundation half-width $b$ constant, decreasing values of $L / b$ reduce the length of piles $L$, and consequently the system stiffness, which results in an increase of the effective period. 
This effect is less appreciable for low values of $h / b$; and this trend is reversed for very low values of this parameter that are not showed in the results presented in this paper. By contrast, in regard to the effective damping ratio, although it is not affected by $L / b$ variations for $1 / \sigma<0.2$, in all cases the decrease of $L / b$ results in a reduction of the system damping for higher values of $1 / \sigma$. This effect decreases for increasing values of $h / b$. It should be noted that for $h / b \geq 5$ the system damping $\tilde{\xi}$ is close to the structural damping $\xi$ and it is not sensitive to $L / b$ variations.

Regarding the effect of the embedment ratio on the maximum structural response $Q_{m}$, the same figure shows that this factor increases with decreasing values of the embedment ratio $L / b$. Generally, this effect is more remarkable for $h / b=2$ and 5 ; however, a change of trend can be observed between the results corresponding to $h / b=5$ and $h / b=10$, respectively, where this effect is not so appreciable. Something similar occurs with the foundation horizontal displacement $\left|\omega_{n}^{2} u_{r}^{c} / \ddot{u}_{g_{o}}\right|$. The foundation rocking $\left|\omega_{n}^{2} h \varphi_{r}^{c} / \ddot{u}_{g_{o}}\right|$, on the other hand, increases for decreasing values of $L / b$, being this effect more noticeable as $h / b$ increases.

\section{CONCLUSIONS}

In this paper, an analysis of the SSI effects on the period and damping of pile-supported structures is accomplished. For this purpose, an equivalence between the interacting system and a SDOF system which reproduces, as accurately as possible, the coupled system response within the range where the peak response occurs is established. The coupled-system response is obtained by using a substructuring model in which the structure is considered as a SDOF shear structure that represents, from a general point of view, one mode of vibration of multi-storey buildings. Both, dynamic and kinematic interaction effects are included in the analysis of this coupled system. Impedances and kinematic interaction factors of the piles configurations studied in this paper, are calculated using a BEM-FEM methodology. In order to determine the dynamic characteristics of this equivalent SDOF system, a simplified and stable procedure, which takes into account all the elements of the matrix of impedances, is developed herein.

Results for 21 different configurations are obtained in order to accomplish an analysis of the influence of the main parameters of the problem for these cases. All the results obtained herein have a dimensionless character, thus their physical interpretation must be carefully done and requires a specific data processing taking into account the influence of every dimensionless parameter.

The conclusions extracted from the analysis are detailed in section 5 and they are consistent with those drawn in relevant literature for embedded foundations. The main conclusions are summarised below.

- Piles configurations which imply stiffer foundations yield a reduction on the effective period of the coupled system: larger number of piles (figure 14) or embedment ratio (figure 16), and lower pile slenderness ratio (figure 15). The obtained results show that this conclusion is not applicable for short and squat buildings, case in which the opposite occurs.

- The effective damping increases with the foundation stiffness (see figures 14, 15 and 16).

- Slender buildings as well as soft soils magnify the SSI effects for a particular configuration. This trend can be reversed for very stiff foundations or very short and squat buildings (see figure 13).

- The effective damping for slender buildings is close to that corresponding to fixed-base condition or lower. For short or medium-height buildings $(h / b<5)$, the effective damping increases as $\sigma$ decreases and this effect becomes more relevant for stiffer piles configurations (see e.g. figures 14 and 16).

- As the influence of the SSI effects increases, the maximum shear force at the base of the structure remains lower than that corresponding to fixed-base condition for buildings with 
$h / b \leq 2$ in all configurations studied. For larger values of the structural slenderness ratio, the maximum shear force increases when these effects are considered (see e.g. figure 15). Stiffer foundations yield lower shear forces if $h / b<5$ (See e.g. figure 14). However, for greater slenderness, the results show variations in the trend that depend on the parameter analyzed.

- The foundation horizontal displacement and rocking increase for softer soils as well as for more flexible geometric configurations (see e.g. figures 15 or 16).

Results in terms of period $\tilde{T} / T$ and damping $\tilde{\xi}$ for different pile configurations are provided in ready-to-use graphs that can be used to build modified response spectra that include SSI effects. Future developments of the presented work would lead to interpolated expressions for the equivalent SDOF system dynamic characteristics that would allow to obtain more accurate design criteria for building structures.

\section{ACKNOWLEDGEMENTS}

This work was supported by the Ministerio de Investigación, Ciencia e Innovación of Spain (MICINN) and FEDER through research project BIA2010-21399-C02-01 and also by the Agencia Canaria de Investigación, Innovación y Sociedad de la Información (ACIISI) of the Government of the Canary Islands and FEDER through research project ProID20100224. C. Medina is a recipient of a fellowship from the Program of predoctoral fellowships of the University of Las Palmas de Gran Canaria (ULPGC). The authors are grateful for this support. The authors would like to thank the reviewers for their valuable suggestions, as they have indeed helped to improve the paper.

\section{References}

[1] P. C. Jennings, J. Bielak, Dynamics of building-soil interaction, Bull Seismol Soc Am 63 (1973) 9-48.

[2] A. S. Veletsos, J. W. Meek, Dynamic behaviour of building-foundation systems, Earthquake Engng Struct Dyn 3 (1974) 121-138.

[3] A. S. Veletsos, V. V. D. Nair, Seismic interaction of structures on hysteretic foundations, J Struct Div, ASCE 101 (1975) 109-129.

[4] J. Bielak, Modal analysis for building-soil interaction, J Engng Mech Div ASCE 102 (1976) 771-786.

[5] J. E. Luco, Linear soil-structure interaction, Technical Report UCRL-15272, Lawrence Livermore National Laboratory, Livermore, California, 1980.

[6] J. P. Wolf, Dynamic soil-structure interaction, Englewood Cliffs, (NJ); Prentice-Hall, 1985.

[7] J. Bielak, Dynamic behaviour of structures with embedded foundations, Earthquake Engng Struct Dyn 3 (1975) 259-274.

[8] J. Avilés, L. E. Pérez-Rocha, Evaluation of interaction effects on the system period and the system damping due to foundation embedment and layer depth, Soil Dyn Earthquake Engng 15 (1996) 11-27.

[9] J. Avilés, L. E. Pérez-Rocha, Effects of foundation embedment during building-soil interaction, Earthquake Engng Struct Dyn 27 (1998) 1523-1540. 
[10] J. Avilés, M. Suárez, F. J. Sánchez-Sesma, Effects of wave passage on the relevant dynamic properties of structures with flexible foundations, Earthquake Engng Struct Dyn 31 (2002) 139-159.

[11] M. I. Todorovska, Effects of the depth of the embedment on the system response during building-soil interaction, Soil Dyn Earthq Eng 11 (1992) 111-123.

[12] M. I. Todorovska, M. D. Trifunac, The system damping, the system frequency and the system response peak amplitudes during in-plane building-soil interaction, Earthquake Engng Struct Dyn 21 (1992) 127-144.

[13] J. Avilés, M. Suárez, Effective periods and dampings of building-foundation systems including seismic wave effects, Engineering Structures 24 (2002) 553-562.

[14] M. I. Todorovska, M. D. Trifunac, Radiation damping during two-dimensional in-plane building-soil interaction, Technical Report 91-01, Department of Civil Engineering. University of Southern California, 1991.

[15] J. H. Rainer, Simplified analysis of dynamic structure-ground interaction, Canadian J Civil Engng 2(3) (1975) 345-356.

[16] A. M. Kaynia, S. Mahzooni, Forces in pile foundations under seismic loading, J Eng Mech 122(1) (1996) 46-53.

[17] H. Aguilar, J. Avilés, Influencia de pilotes de fricción en la interacción dinámica sueloestructura, Rev Int Mt Num Clc Dis Ing 19,1 (2003) 3-18.

[18] A. Maravas, G. Mylonakis, D. Karabalis, Dynamic characteristics of simple structures on piles and footings, in: Proc. of 4th Int Conf on Earthquake Geotech Eng, no. 1672, Thessaloniki, Greece.

[19] L. A. Padrón, J. J. Aznárez, O. Maeso, 3-D boundary element - finite element method for the dynamic analysis of piled buildings, Eng Anal Bound Elem 35 (2011) 465-477.

[20] R. A. Parmelee, Building-foundation interaction effects, J Eng Mech Div, ASCE 93 (1967) 131-162.

[21] E. Kausel, J. M. Roësset, Soil-structure interaction for nuclear containment, in: Electric Power and Civil Engineer. Power Div. ASCE Specialty Conf, Boulder, Colorado, pp. 469498.

[22] B. Verbic, A. S. Veletsos, Impulse response functions for elastic foundations, Technical Report SRR 15, Department of Civil Engineering, Rice University, Houston, Texas, 1972.

[23] A. K. Chopra, Dynamic of structures. Theory and applications to earthquake engineering., Prentice-Hall (NJ), 2001.

[24] R. W. Clough, J. Penzien, Dynamics of Structures, McGraw-Hill, 1982.

[25] J. E. Luco, Soil-structure interaction and identification of structural models, in: Proc. ASCE Speciality Conf. in Civil Engineering and Nuclear Power, Knoxville, Tennessee.

[26] E. Kausel, Structures in seismic regions, Technical Report, Technische universitt Berlin and MIT, 1984.

[27] G. Gazetas, K. Fan, T. Tazoh, K. Shimizu, M. Kavvadas, N. Makris, Seismic pilegroupstructure interaction, Geothec Spec Publ, ASCE 34 (1992) 56-93. 
[28] J. P. Stewart, R. B. Seed, G. L. Fenves, Seismic soil-structure interaction in buildings. ii: Empirical findings., J. Geotech. Engrg., ASCE 125(1) (1999) 38-48.

[29] G. Gazetas, Foundation Vibrations. Foundation Engineering Handbook, H Fang (Ed), Van Nostrand Reinhold, NY, 1991.

[30] R. Dobry, G. Gazetas, Simple method for dynamic stiffness and damping of floating pile groups, Géothenique 38 (1988) 557-574.

[31] H. G. Poulos, Analysis of displacements of laterally loaded piles II - Pile groups, J Soil Mech Found Div, ASCE 97(5) (1971) 733-751.

[32] K. Konagai, R. Ashan, D. Maruyama, Simple expression of the dynamic stiffness of grouped piles in sway motion, Journal of Earthquake Engineering 4(3) (2000) 355-376.

[33] R. Taherzadeh, D. Clouteau, R. Cottereau, Simple formulas for the dynamic stiffness of pile groups, Earthquake Engng Struct Dyn 38 (2009) 1665-1685.

[34] W. Dai, J. M. Roësset, Horizontal dynamic stiffness of pile groups: Approximate expression, Soil Dyn Earthq Eng 30 (2010) 844-850.

[35] S. M. Mamoon, P. K. Banerjee, Response of piles and pile groups to travelling SH-waves, Earthquake Eng Struct Dyn 19 (1990) 597-610.

[36] K. Fan, G. Gazetas, A. M. Kaynia, E. Kausel, S. Ahmad, Kinematic seismic response of single piles and pile groups, J Geothec Eng Div, ASCE 117(12) (1991) 1860-1879.

[37] M. Kavvadas, G. Gazetas, Kinematic seismic response and bending of free-head piles in layered soil, Geothécnique 43 (1993) 207-222.

[38] A. M. Kaynia, E. Kausel, Dynamic stiffness and seismic response of pile groups, Technical Report R83-03, MIT, Cambridge, MA, 1982.

[39] L. A. Padrón, J. J. Aznárez, O. Maeso, BEM-FEM coupling model for the dynamic analysis of piles and pile groups, Eng Anal with Boundary Elem 31 (2007) 473-484.

[40] L. A. Padrón, J. J. Aznárez, O. Maeso, Dynamic analysis of piled foundations in stratified soils by a BEM-FEM model, Soil Dyn Earthquake Eng 28 (2008) 333-346.

[41] L. A. Padrón, J. J. Aznárez, O. Maeso, Dynamic stiffness of deep foundations with inclined piles, Earthquake Engng Struct Dyn 39(12) (2010) 1343-1367.

[42] K. Miura, A. M. Kaynia, K. Masuda, E. Kitamura, Y. Seto, Dynamic behaviour of pile foundations in homogeneous and non-homogeneous media, Earthquake Engng Struct Dyn 23 (1994) 183-192.

[43] G. D. Manolis, D. E. Beskos, Boundary element methods in elastodynamics, Unwin-Hyman, London, 1988.

[44] J. Domínguez, Boundary elements in dynamics, Computational Mechanics Publications \& Elsevier Applied Science, Southampton, NY, Southampton-New York, 1993.

[45] S. Nikolaou, G. Mylonakis, G. Gazetas, T. Tazoh, Kinematic pile bending during earthquakes: Analysis and field measurements, Géothecnique 51(5) (2001) 425-440. 

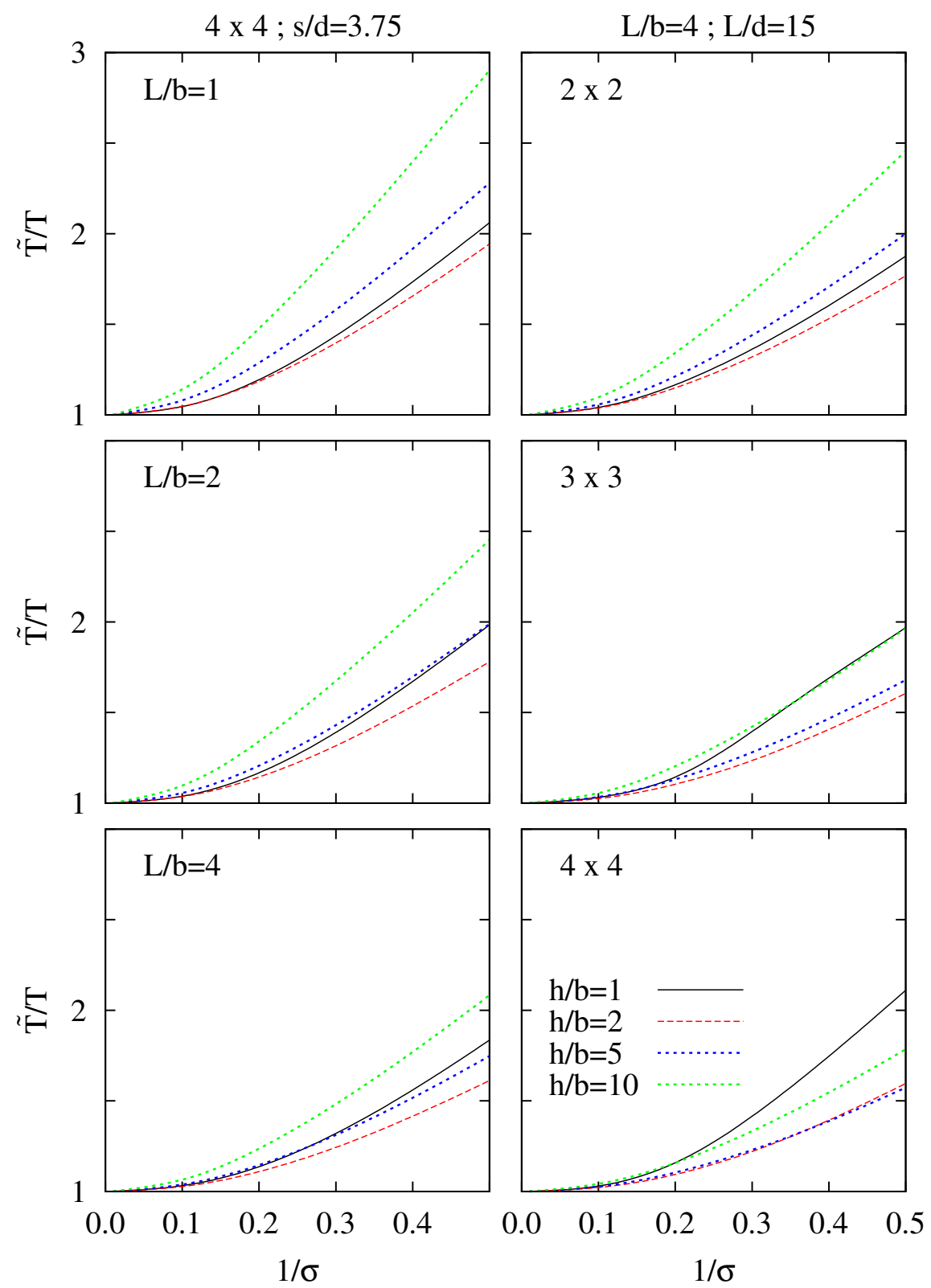

Figure 13: Effective period $\tilde{T} / T$ for a $4 \times 4$ pile group with $s / d=3.75$ (left column) and for a pile group with $L / b=4, L / d=15$ (right column). $E p / E s=10^{3}$ and $\xi_{s}=0.05$. Influence of the structural slenderness ratio $h / b$. 

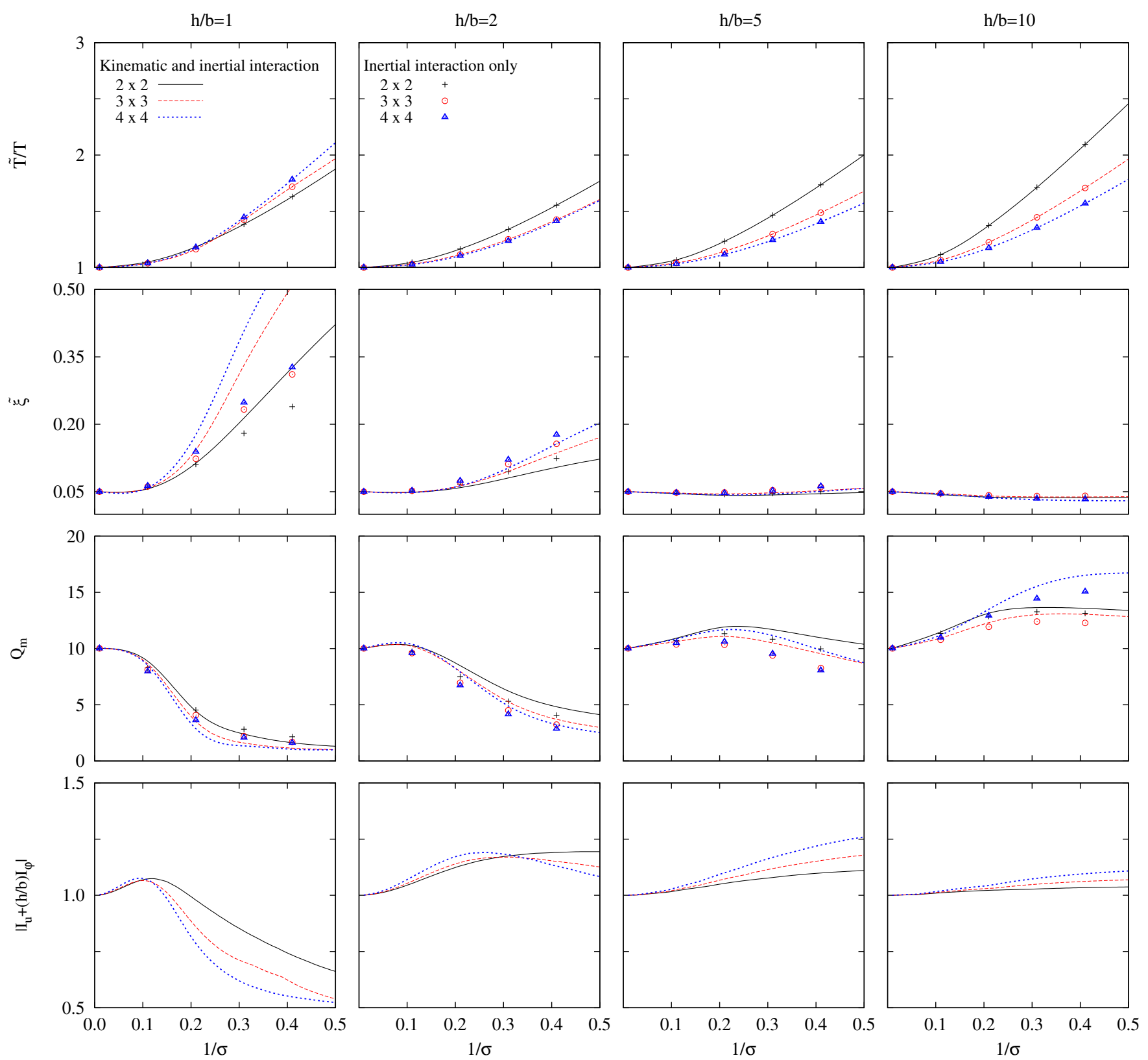

Figure 14: Effective period $\tilde{T} / T$, damping ratio $\tilde{\xi}$, maximum structural response value $Q_{m}$ and kinematic interaction factor $\left|I_{u}+(h / b) I_{\varphi}\right|$ for pile groups with $L / b=4, L / d=15, E p / E s=10^{3}$ and $\xi_{s}=0.05$. Influence of the kinematic interaction and the size of the pile group. 

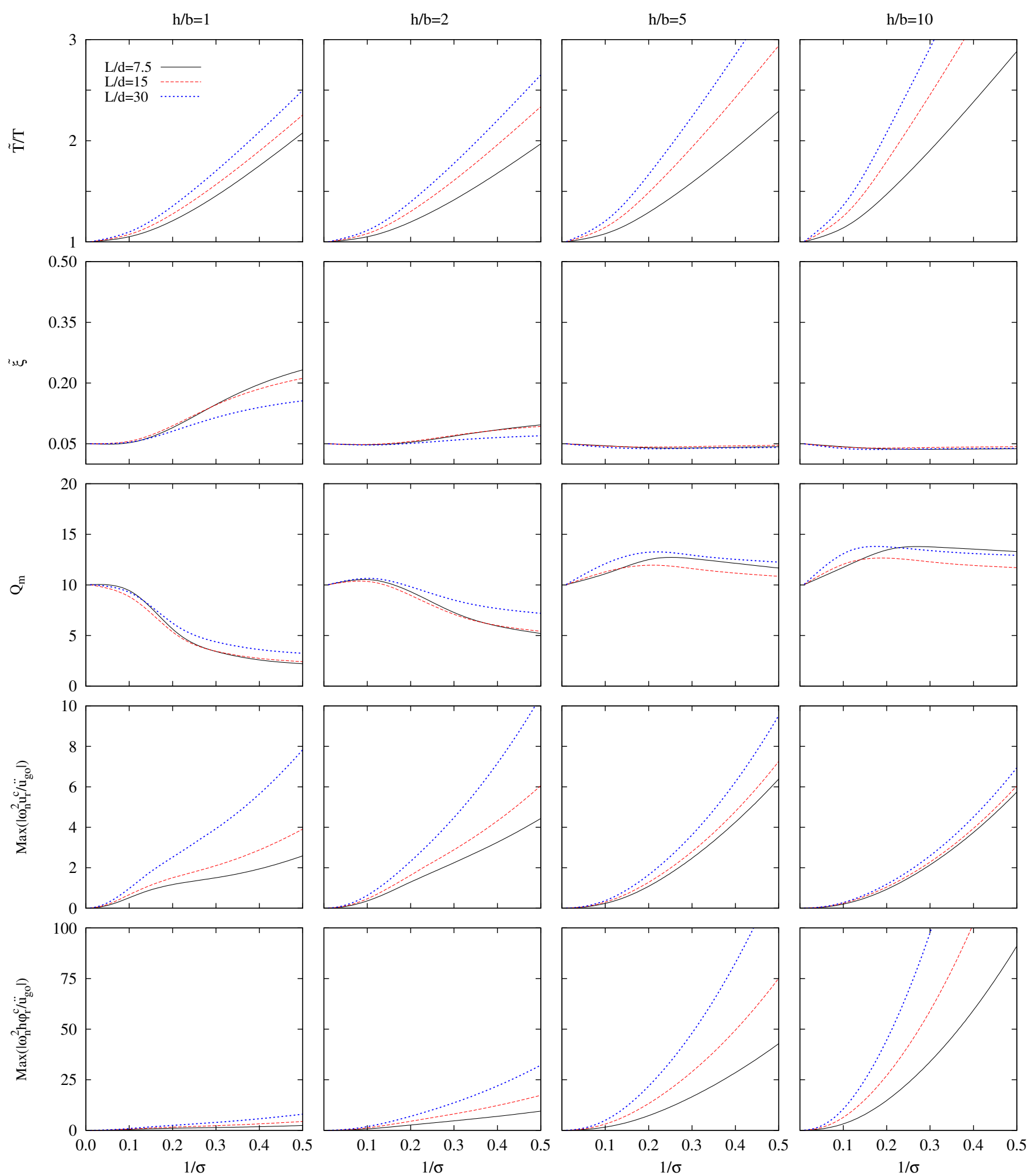

Figure 15: Effective period $\tilde{T} / T$, damping ratio $\tilde{\xi}$, maximum structural response value $Q_{m}$ and maximum relative values of the foundation horizontal displacement $\left|\omega_{n}^{2} u_{r}^{c} / \ddot{u}_{g_{o}}\right|$ and rocking $\left|\omega_{n}^{2} h \varphi_{r}^{c} / \ddot{u}_{g_{o}}\right|$ for a $2 \times 2$ pile group with $L / b=2, E p / E s=10^{3}$ and $\xi_{s}=0.05$. Influence of the pile slenderness ratio $L / d$. 

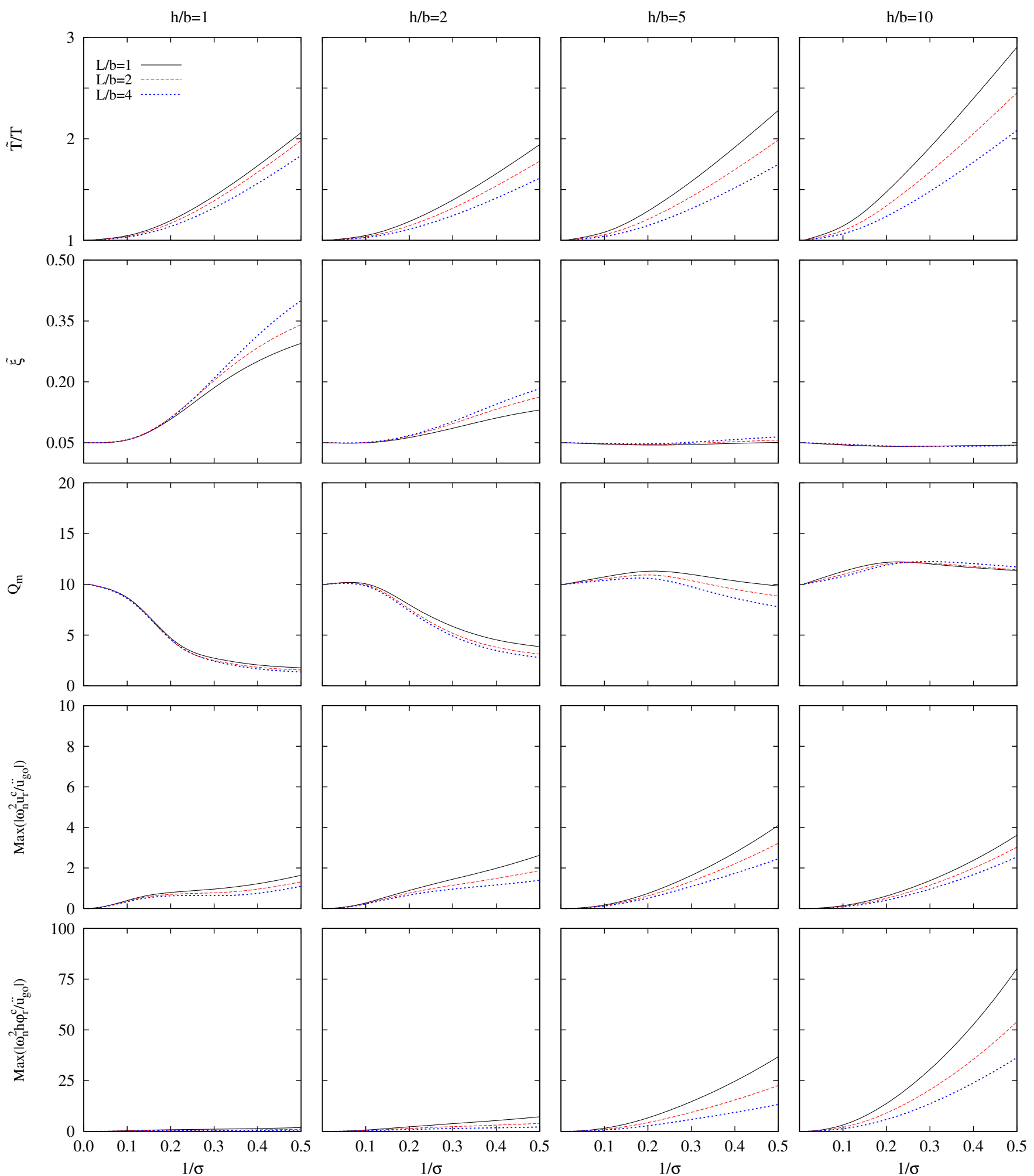

Figure 16: Effective period $\tilde{T} / T$, damping ratio $\tilde{\xi}$, maximum structural response value $Q_{m}$ and maximum relative values of the foundation horizontal displacement $\left|\omega_{n}^{2} u_{r}^{c} / \ddot{u}_{g_{o}}\right|$ and rocking $\left|\omega_{n}^{2} h \varphi_{r}^{c} / \ddot{u}_{g_{o}}\right|$ for a $4 \times 4$ pile group with $s / d=3.75, E p / E s=10^{3}$ and $\xi_{s}=0.05$. Influence of the embedment ratio $L / b$. 